\title{
An extended Kalman-filter for regional scale inverse emission estimation
}

\author{
D. Brunner ${ }^{1}$, S. Henne ${ }^{1}$, C. A. Keller ${ }^{1}$, S. Reimann ${ }^{1}$, M. K. Vollmer ${ }^{1}$, S. O'Doherty ${ }^{2}$, and M. Maione ${ }^{3}$ \\ ${ }^{1}$ Empa, Swiss Federal Laboratories for Materials Science and Technology, Dübendorf, Switzerland \\ ${ }^{2}$ School of Chemistry, University of Bristol, Bristol, UK \\ ${ }^{3}$ Dipartimento di Scienze di Base e Fondamenti (DiSBeF), University of Urbino "Carlo Bo", Urbino, Italy
}

Correspondence to: D. Brunner (dominik.brunner@empa.ch)

Received: 27 September 2011 - Published in Atmos. Chem. Phys. Discuss.: 28 October 2011

Revised: 17 February 2012 - Accepted: 2 April 2012 - Published: 11 April 2012

\begin{abstract}
A Kalman-filter based inverse emission estimation method for long-lived trace gases is presented for use in conjunction with a Lagrangian particle dispersion model like FLEXPART. The sequential nature of the approach allows tracing slow seasonal and interannual changes rather than estimating a single period-mean emission field. Other important features include the estimation of a slowly varying concentration background at each measurement station, the possibility to constrain the solution to non-negative emissions, the quantification of uncertainties, the consideration of temporal correlations in the residuals, and the applicability to potentially large inversion problems. The method is first demonstrated for a set of synthetic observations created from a prescribed emission field with different levels of (correlated) noise, which closely mimics true observations. It is then applied to real observations of the three halocarbons HFC-125, HFC-152a and HCFC-141b at the remote research stations Jungfraujoch and Mace Head for the quantification of emissions in Western European countries from 2006 to 2010. Estimated HFC-125 emissions are mostly consistent with national totals reported to UNFCCC in the framework of the Kyoto Protocol and show a generally increasing trend over the considered period. Results for HFC152a are much more variable with estimated emissions being both higher and lower than reported emissions in different countries. The highest emissions of the order of 700$800 \mathrm{Mg} \mathrm{yr}^{-1}$ are estimated for Italy, which so far does not report HFC-152a emissions. Emissions of HCFC-141b show a continuing strong decrease as expected due to its controls in developed countries under the Montreal Protocol. Emissions from France, however, were still rather large, in the range of
\end{abstract}

$700-1000 \mathrm{Mg} \mathrm{yr}^{-1}$ in the years 2006 and 2007 but strongly declined thereafter.

\section{Introduction}

The atmosphere acts as an integrator in which emission fluxes from individual sources get gradually mixed by atmospheric transport processes. Atmospheric trace gas observations therefore integrate information on a multitude of sources, and it is the goal of inverse emission modeling to retrieve the original fluxes from individual sources (or usually aggregated sources) by accounting for the effect of atmospheric transport and mixing, and in case of reactive or soluble gases for chemical conversion and removal. Inverse emission estimation is rapidly gaining in popularity as several studies have demonstrated its value for understanding natural carbon fluxes (Houweling et al., 1999; Gurney et al., 2002; Rayner et al., 2008; Bousquet, 2009) and for evaluating classical "bottom-up" inventories (Bergamaschi et al., 2005; Chen and Prinn, 2006; Vollmer et al., 2009). Furthermore, "top-down" emission estimation as provided by inverse methods may provide up-to-date information for policymakers to monitor the success of their emission reduction or mitigation measures.

Bottom-up inventories as compiled by individual nations are typically obtained by combining emission factors for individual processes with statistical information on the activity of those processes. Examples are the European EMEP Centre on Emissions and Projections (CEIP, http://www.ceip.at/) inventory of atmospheric constituents relevant for human 
health and ecosystems, or the United Nations Framework Convention on Climate Change (UNFCCC, http://unfecc.int) database of national greenhouse gas emissions. Despite large efforts for homogenization of methods and validation, there are considerable uncertainties involved in all steps of generation of these inventories (Winiwarter and Rypdal, 2001) and many countries have only limited resources to collect the necessary information. For the purpose of atmospheric modeling, spatially explicit, i.e. gridded inventories have been developed such as the Emission Database for Global Atmospheric Research (EDGAR, http://edgar.jrc.ec.europa.eu/ index.php) (Olivier et al., 2002).

There is a strong need for independent verification of inventories, particularly in the context of international treaties on climate, air quality, and the protection of the ozone layer. Previous studies have pointed out the great potential of topdown estimation of greenhouse gas emissions (e.g., Houweling et al., 1999; Bergamaschi et al., 2005; Bousquet et al., 2006; Rayner et al., 2008; Göckede et al., 2010; Hirsch et al., 2006) but they also revealed often large and poorly quantified uncertainties associated with this approach (e.g., Kaminski et al., 2001; Engelen et al., 2006; Gurney et al., 2002; Lin and Gerbig, 2005; Baker et al., 2006).

In this study we present an emission estimation approach generally applicable to long-lived or weakly reactive trace gases with only positive surface fluxes (emissions), i.e. trace gases with negligible deposition/uptake at the surface. The method is demonstrated for halocarbons which are measured quasi-continuously at only few sites in Europe, and the ability to invert emissions on a country-by-country basis is explored. Chlorinated and brominated halocarbons including chlorofluorocarbons (CFCs) and bromocarbons (halons) are harmful to the ozone layer and have therefore been banned under the Montreal Protocol (World Meteorological Organization, 2007). They have first been substituted by hydrochlorofluorocarbons (HCFCs) which have shorter lifetimes and therefore lower ozone depletion potentials (ODPs). HCFCs are currently being replaced by chlorine-free hydrofluorocarbons (HFCs) with zero ODP. However, like CFCs and HCFCs these HFCs are often potent greenhouse gases contributing to global warming and are therefore included in the Kyoto Protocol. Without further regulation, their continued growth in the atmosphere will lead to a non-negligible contribution to radiative forcing equivalent to $7-12 \%$ of the radiative forcing of $\mathrm{CO}_{2}$ by the year 2050 as shown by (Velders et al., 2009) for a scenario in which it was assumed that developing countries replace HCFCs in the same manner as developed countries have.

Top-down estimation of halocarbon emissions has a long tradition (see Prinn et al. (2000) and references therein). One-box and multi-box-models were applied to derive hemispheric or global mean emissions based on simple budget considerations (Cunnold et al., 1994; Montzka et al., 1999; Vollmer et al., 2006; World Meteorological Organization, 2007; O'Doherty et al., 2009). Three-dimensional transport models were used to estimate the large-scale distribution of global emissions (Hartley and Prinn, 1993; Mahowald et al., 1997; Mulquiney et al., 1998) employing monthly or annual mean observations with pollution events filtered out to eliminate the effect of regional and local emissions not represented by the coarse models. A fundamentally different approach is required when regional scale emissions are addressed. Information on regional emissions is largely contained in the observed pollution events, which as part of the whole observational dataset can be used to quantify sources in the surroundings of a measurement site. The large-scale background, in turn, which represents the accumulated effect of past emissions already diluted over a large domain, needs to be subtracted. Regional inversions also require higher resolution transport models and typically rely on measurements from stations located closer to emission sources than the mostly remote stations set up in networks such as AGAGE and NOAA ESRL/GMD designed to characterize the large-scale background (Bergamaschi et al., 2005). Additionally, a dense network of stations would be desirable (Villani et al., 2010) but this is currently not available for halocarbons.

Two possible approaches for combining the benefits of global and regional inversions have recently been proposed by Rödenbeck et al. (2009) and Rigby et al. (2011). These approaches essentially separate the concentration field into a component generated by regional emissions within a nested domain and a (smooth) background component from emissions outside of this domain plus regional emissions that temporally left the domain and typically circulated the globe before reentering.

This study addresses the second type of inversions targeting at the regional scale and attempts to estimate the background component directly without requiring another globalscale transport model as in the studies of Rödenbeck et al. (2009) and Rigby et al. (2011). It builds on the expertise developed in previous studies and presents an alternative approach applicable in combination with a Lagrangian transport model. In a similar study, Manning et al. (2003) used the NAME model together with a best fit method by simulated annealing to estimate Western European emissions of ozone depleting and greenhouse gases measured at Mace Head. More closely related to the present work from a methodological point of view is the approach presented by Stohl et al. (2009) which used the FLEXPART transport model in combination with a least-squares Bayesian inversion. The method was first applied to estimate global emissions of a suite of halocarbons measured at AGAGE and related networks (Stohl et al., 2009) and subsequently to quantify emissions from East Asia (Vollmer et al., 2009; Stohl et al., 2010) and Europe (Keller et al., 2011, 2012). Here we explore the potential of a third approach based on the Kalman filter.

Kalman filtering had also been the mathematical foundation of the studies of Hartley and Prinn (1993), Mulquiney et al. (1998) and Bruhwiler et al. (2005) which, however, were tailored for global-scale inversions. The specific 
advantages of our method include easy handling of large inversion problems (many observations, many unknowns), direct and consistent estimation of a smoothly varying concentration background at each station, estimation of a slowly varying emission field rather than assuming temporally constant emissions, quantification of uncertainties, and objective determination of the tuning parameters of the inversion.

The method and data sets used are described in Sect. 2. The performance of the inversion is tested in Sect. 3 through a number of sensitivity runs using pseudo-observations. Finally, it is applied in Sect. 4 to real observations from the stations Jungfraujoch, Switzerland, and Mace Head, Ireland, to quantify the emissions of HFC-125 $\left(\mathrm{CHF}_{2} \mathrm{CF}_{3}\right), \mathrm{HFC}-152 \mathrm{a}$ $\left(\mathrm{CH}_{3} \mathrm{CHF}_{2}\right)$, and HCFC-141b $\left(\mathrm{CH}_{3} \mathrm{CCl}_{2} \mathrm{~F}\right)$. The impact of adding the station Monte Cimone in Italy is also demonstrated, and a comparison with a Bayesian inversion is presented.

\section{Data and methods}

\subsection{Halocarbon observations}

The inversion method is applied to halocarbon observations collected between 2006 and 2010 at the high alpine site Jungfraujoch in the Bernese Alps of Switzerland $\left(7.99^{\circ} \mathrm{E} / 46.55^{\circ} \mathrm{N}, 3580 \mathrm{~m}\right.$ a.s.l.) and the coastal background site Mace Head, Ireland $\left(-9.90^{\circ} \mathrm{E} / 53.33^{\circ} \mathrm{N}, 25 \mathrm{~m}\right.$ a.s.l.). Mace Head and Jungfraujoch both contribute to the Advanced Global Atmospheric Gases Experiment (AGAGE) network (Prinn et al., 2000). Together with the stations Monte Cimone, Italy, and Zeppelin, Spitsbergen, they are the only sites in Europe with quasi-continuous measurements of these gases. From 2000 to 2008, halocarbons were measured at Jungfraujoch by a gas chromatography - mass spectrometry (GCMS) system coupled to the Adsorption-Desorption System (ADS) pre-concentration unit (Simmonds et al., 1995). Measurement intervals were $4 \mathrm{~h}$ which included both ambient air samples and reference measurements. In 2008 a new GCMS system coupled to the "Medusa" preconcentration unit was deployed, which allows for more frequent observations every $2 \mathrm{~h}$ and the detection of more species with better precisions (Miller et al., 2008). Measurements at Mace Head began in October 1994 using a GCMS-ADS system and switched to a GCMS-Medusa in November 2003. The measurements at the two stations are traced back to the standards of the global AGAGE network (University of Bristol calibration scale UB-98 for HFC-125; Scripps Institution of Oceanography calibrations scale SIO-05 for HFC-152a and HCFC-141b (Prinn et al., 2000; Miller et al., 2008)).

Time series of halocarbons measured at Jungfraujoch and Mace Head during the five years 2006-2010 are shown in Fig. 1 for HFC-125, HFC-152a and HCFC-141b. HFC-125 is widely used as cooling agent for commercial refrigeration and to a minor extent as fire extinguishing equipment
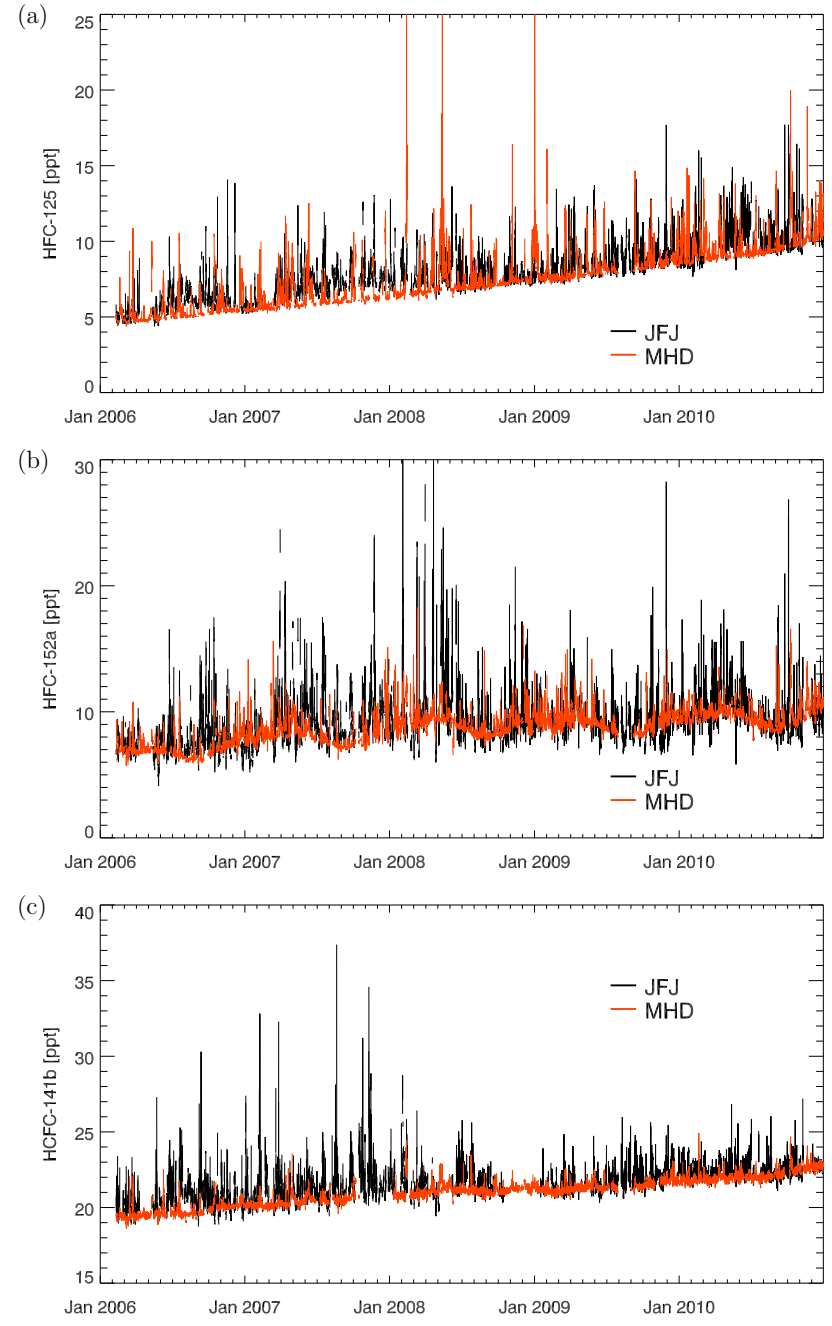

Fig. 1. Time series of (a) HFC-125, (b) HFC-152a, and (c) HCFC$141 \mathrm{~b}$ measured at Jungfraujoch (black) and Mace Head (red) during the five years 2006 to 2010 .

(O'Doherty et al., 2009; Velders et al., 2009). HFC-152a is primarily used for foam blowing (Greally et al., 2007). HCFC-141b is used as a solvent and foam blowing agent in the manufacture of diverse products ranging from refrigerators to building insulation. Due to its significant ODP of 0.11 its production and use is being phased out in industrialized countries in a stepwise manner since January 2004 (Derwent et al., 2007). This likely explains the decrease in the amplitude of concentration peaks at Jungfraujoch and the general leveling off of its background concentration increase. While the magnitude of pollution peaks is comparable at the two stations in the case of HFC-125, peaks of HFC-152a and HCFC-141b are much smaller at Mace Head than at Jungfraujoch suggesting that their main sources are far away from Mace Head, likely not in Ireland or the UK. The location of Jungfraujoch and Mace Head is displayed in Fig. 2 overlaid over the combined footprint of the emission 


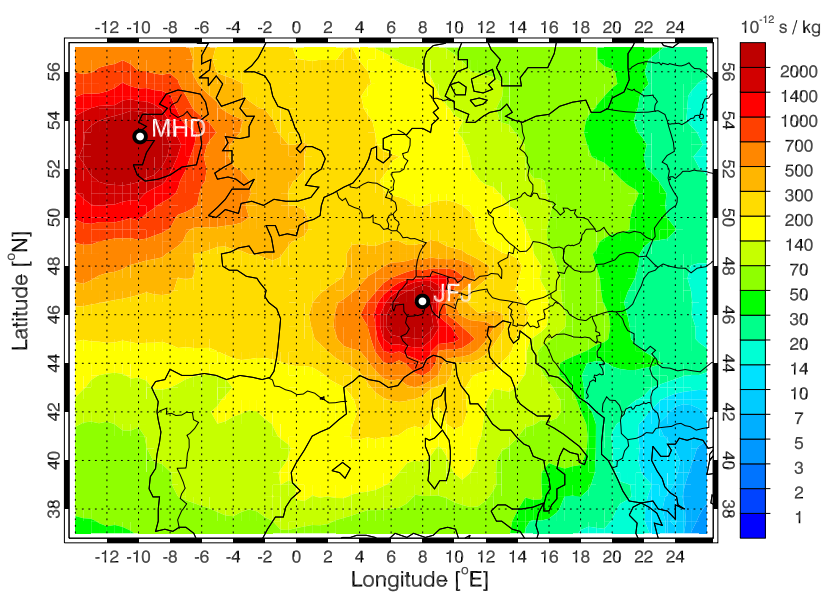

Fig. 2. Footprint emission sensitivity (in picoseconds per kilogram) averaged over all air masses arriving at Jungfraujoch (JFJ) and Mace Head (MHD) between February 2006 and December 2010.

sensitivity of the two stations averaged over the period February 2006 to December 2010 (see next section). The figure highlights the radially decreasing sensitivity with increasing distance from the sites. Due to the prevailing westerly to southwesterly flow, this decrease is steeper towards the east. As a consequence, countries in the eastern part of Europe are only poorly covered. In this study we will therefore focus on emissions from the countries Switzerland, Austria, Italy, Spain, France, The Netherlands, Belgium, Germany, $\mathrm{UK}$, and Ireland.

Jungfraujoch (JFJ) is located on a saddle between the two mountains Jungfrau $(4158 \mathrm{~m})$ and Mönch $(4107 \mathrm{~m})$. It is mostly sampling free tropospheric air but on sunny days in spring and summer the atmospheric boundary layer often influences the station in the afternoon, supported by thermallyinduced wind systems and convection over the Alpine topography (Nyeki et al., 2000; Henne et al., 2005; Collaud Coen et al., 2011). Apart from this rather local influence in spring and summer, Jungfraujoch is frequently affected by largescale uplift from the European boundary layer usually in connection with fronts (Seibert et al., 1998; Reimann et al., 2008). This gives rise to the numerous pollution peaks seen in Fig. 1 which last between a few hours and a few days and allow us to infer halocarbon emissions for large parts of Western Europe.

Previous studies showed that the complex Alpine topography poses a great challenge for any model to accurately describe the transport to Jungfraujoch (Seibert et al., 1998; Folini et al., 2008). Stohl et al. (2009) in fact concluded that Jungfraujoch is not well suited for atmospheric inversions due to these difficulties. It is important to note that we have been able to significantly improve the representation of transport by using higher resolution meteorological input data (at $0.2^{\circ} \times 0.2^{\circ}$ versus $1^{\circ} \times 1^{\circ}$ ) and by choosing a release altitude lower than the true station altitude but still well above the model topography. As will be shown later, our simulations for HFC-125 can explain more than $40 \%$ of the observed variance $\left(r^{2}>0.4\right)$ as opposed to the very low value of $4 \%$ reported by Stohl et al. (2009) for HFC-134a.

The Mace Head atmospheric research station is situated on the west coast of Ireland. It is one of only a few clean background Western European stations, thus providing an essential baseline input for inter-comparisons with continental Europe, whilst also acting as a baseline site representative of northern hemispheric air. Prevailing winds from the west to southwest sector bring clean background air to the site that has passed over several thousand kilometers of the North Atlantic (O'Doherty et al., 2001, 2009; Derwent et al., 2007). Polluted European air masses as well as tropical maritime air masses cross the site periodically. Mace Head is therefore uniquely positioned for resolving these air masses and for comparative studies of their composition. Galway is the closest city, with a population of 72000 , located $50 \mathrm{~km}$ to the east whilst the area immediately surrounding Mace Head is very sparsely populated providing very low local anthropogenic emissions. In contrast to Jungfraujoch, pollution events observed at Mace Head are mostly well captured by transport models. The transport towards Jungfraujoch and Mace Head was recently compared with that of other remote and rural sites in Europe and it was concluded that both sites fall into the remote category with an intermittent PBL influence for Jungfraujoch (Henne et al., 2010).

As seen in Fig. 2, the footprint of emissions covered by the two measurement sites is far from ideal. Additional sites would be desirable to better cover Eastern Europe, Spain and Scandinavia. The spatial allocation of sources becomes much more robust when the same sources are observed from multiple sites from different directions. We will demonstrate the effect of adding the station Monte Cimone south of the Alps, which provides a much better constraint for emissions from Italy as well as the Iberian Peninsula. The great value of adding a site in Hungary for better coverage of Eastern Europe was recently demonstrated by Keller et al. (2012).

\subsection{Backward transport simulations}

The Lagrangian Particle Dispersion Model FLEXPART (Stohl et al., 2005) was used in backward (receptor-oriented) mode to establish the relation between potential sources and the receptor locations Jungfraujoch and Mace Head. FLEXPART describes the evolution of a dispersing plume by simulating the transport of "particles", i.e. infinitesimally small elements of air, by the 3-dimensional grid-resolved wind and by subgrid-scale turbulent and convective motion. As input for the model meteorological fields from the European Centre for Medium Range Weather Forecasts (ECMWF) at $3 \mathrm{~h}$ temporal resolution (alternating between 6 hourly analyses and analysis $+3 \mathrm{~h}$ forecasts) were used. The fields were available globally at $1^{\circ} \times 1^{\circ}$ horizontal and 91 levels vertical resolution and at a much higher horizontal resolution 
of $0.2^{\circ} \times 0.2^{\circ}$ for a nested domain covering Central Europe $\left(4^{\circ} \mathrm{W}-16^{\circ} \mathrm{E}, 39-51^{\circ} \mathrm{N}\right)$ to better describe transport to Jungfraujoch. Despite the higher resolution, the model topography at the position of Jungfraujoch is only at about $2100 \mathrm{~m}$ a.s.l., thus $1500 \mathrm{~m}$ below the true station altitude. To find an optimal release altitude for the Lagrangian particles, which may be at some intermediate level between model surface and true station altitude, several simulations of carbon monoxide concentrations using the EMEP Centre on Emission Inventories and Projections (CEIP, http://www.ceip.at/) emissions inventory and releasing particles between $2500 \mathrm{~m}$ and $3580 \mathrm{~m}$ were performed. These simulations indicated that a release altitude of about $3000 \mathrm{~m}$ performs best. Correlation coefficients $r$ between simulated $\mathrm{CO}$ and observed $\mathrm{CO}$ minus background in the year 2008 were 0.59 for $3000 \mathrm{~m}$, 0.55 for $3580 \mathrm{~m}$ and only 0.49 for $2500 \mathrm{~m}$. A release altitude of $3000 \mathrm{~m}$ was therefore chosen for all Jungfraujoch simulations. The sensitivity to this choice will briefly be discussed in Sect. 4.1.

For each 3-h time interval during the period 10 February 2006 to 31 December 201050000 particles were released from each station and traced backward in time for 5 days to compute the source-receptor relationship (SRR) or "footprint" (Seibert and Frank, 2004). The SRR value (in units of $\mathrm{s} \mathrm{kg}^{-1}$ ) is proportional to the particle residence time in a grid cell and measures the simulated mixing ratio at the receptor that a source of unit strength $(1 \mathrm{~kg})$ would produce. SRRs were computed based on particle residence times within the lowest $100 \mathrm{~m}$ above surface mapped onto a grid of $0.5^{\circ} \times 0.5^{\circ}$ horizontal resolution. The studies of Folini et al. (2008) and Stohl et al. (2009) concluded that 5 days is sufficient to capture the influence of European emissions under most situations. The start date of the simulation period was selected based on the fact that in February 2006 the ECMWF IFS model was switched to a higher resolution (T799, $91 \mathrm{lev}$ els). Only this change allowed us to perform simulations at approximately $20 \mathrm{~km}$ resolution within the nested domain. Each 3-h interval was associated with a corresponding trace gas concentration by averaging the measurements available within the interval or, in case of the 4-hourly ADS measurements, by interpolation of the closest two observations.

\subsection{Inversion method}

The emission distribution is inversely determined by sequential assimilation of observations using an extended Kalman filter. The Kalman filter is a widely applicable tool to estimate the parameters of a dynamic system by optimally combining a physical or empirical model of the system with observations of its evolving state (Kalman and Bucy, 1961). For a system that evolves according to a linear model, the Kalman filter provides a recursive computation of the best linear unbiased estimate of the state variable (and its covariance) at time $k$ based on partial and noisy measurements up to the same time. Optimality of the filter requires unbiased and uncorrelated observations.

Let $\boldsymbol{x}_{k}$ be the vector of the true non-observable state at time $k$. In our case it will be composed of the logarithm of the gridded emissions $x_{k}^{\mathrm{e}}\left(=\ln \left(\mathbf{e}_{k}\right)\right)$, the background concentrations at the stations $\boldsymbol{x}_{k}^{\mathrm{b}}$ and optionally other parameters $\boldsymbol{x}_{k}^{\mathrm{o}}$ as described below, hence $\boldsymbol{x}_{k}=\left(\boldsymbol{x}_{k}^{\mathrm{e}}, \boldsymbol{x}_{k}^{\mathrm{b}}, \boldsymbol{x}_{k}^{\mathrm{o}}\right)$. The logarithm is taken to constrain emissions to positive values but it also ensures that residuals (differences between modeled and measured values) closely follow Gaussian probability distributions, a prerequisite for successful Kalman filtering. Note, however, that this limits the applicability of the method to trace gases with only positive fluxes (emissions) and would not be valid for species like $\mathrm{CO}_{2}$ with important negative fluxes. The idea of including the background concentrations in the state vector is that an observed concentration can be decomposed into a (large scale) background plus a contribution from recent emissions as covered by the transport model simulation, in our case from the previous 5 days.

The evolution with time is described by a linear model $\mathbf{D}_{k}$ which provides a prediction of the state at time $k$ from the previous time $k-1$ :

$\boldsymbol{x}_{k}=\mathbf{D}_{k} \boldsymbol{x}_{k-1}+\eta_{k}$, with $\eta_{k} \sim N\left(0, \mathbf{Q}_{k}\right)$.

where $\eta_{k}$ is the error of the prediction step with zero mean and covariance matrix $\mathbf{Q}_{k}$. For the emissions we assume persistence, that is no change from time $k-1$ to time $k$ except for a random component $\eta_{k}^{\mathrm{e}}$. When it is not known a priori how emissions are changing with time, a persistence model provides the best prediction for the next time step.

The upper left square of matrix $\mathbf{D}_{k}$, which applies to the emissions part of the state vector, is thus the identity matrix. For the background we either assume persistence as well or that it follows a linear trend. In the latter case, the state vector is augmented by a background trend per station $\boldsymbol{x}_{k}^{\mathrm{t}}$ to be estimated by the Kalman filter. This is one of two optional components of $\boldsymbol{x}_{k}^{\mathrm{o}}$. For a single station the prediction equation for the background and the background trend takes the form

$\left(\begin{array}{c}x_{k}^{\mathrm{b}} \\ x_{k}^{\mathrm{t}}\end{array}\right)=\left(\begin{array}{ll}1 & 1 \\ 0 & 1\end{array}\right)\left(\begin{array}{c}x_{k-1}^{\mathrm{b}} \\ x_{k-1}^{\mathrm{t}}\end{array}\right)+\left(\begin{array}{c}\eta_{k}^{\mathrm{b}} \\ \eta_{k}^{\mathrm{t}}\end{array}\right)$.

Extension to more stations is straightforward. With this equation we thus assume persistence of the trend (i.e. the first derivative) rather than of the background itself.

So far $\boldsymbol{x}_{k}$ described the true non-observable state. We now introduce the analysis vector $\boldsymbol{x}_{k}^{+}$, which will be our best estimate of $\boldsymbol{x}_{k}$ at time $k$

$\boldsymbol{x}_{k}^{+}=\boldsymbol{x}_{k}+\epsilon_{k}, \quad$ with $\epsilon_{k} \sim N\left(0, \mathbf{P}_{k}^{+}\right)$

which differs from the true state by the analysis error $\epsilon_{k}$ with zero mean and covariance matrix $\mathbf{P}_{k}^{+}$. 
Equation (1) provides the recipe to obtain a first guess $\boldsymbol{x}_{k}^{-}$ of the state at time $k$ from the previous analysis at time $k-1$

$\boldsymbol{x}_{k}^{-}=\mathbf{D}_{k} \boldsymbol{x}_{k-1}^{+}+\eta_{k}, \quad$ with $\quad \eta_{k} \sim N\left(0, \mathbf{Q}_{k}\right)$.

The uncertainty $\mathbf{P}_{k}^{-}$of $\boldsymbol{x}_{k}^{-}$is given by

$\mathbf{P}_{k}^{-}=\mathbf{D}_{k} \mathbf{P}_{k-1}^{+} \mathbf{D}_{k}^{T}+\mathbf{Q}_{k}$.

Since the matrix $\mathbf{D}_{k}$ is almost diagonal with only few nonzero off-diagonal elements, we compute the few non-zero terms in Eq. (5) explicitly rather than performing the expensive full matrix multiplication.

Next we consider the assimilation of observations which translates the first guess $\boldsymbol{x}_{k}^{-}$into an analysis $\boldsymbol{x}_{k}^{+}$at time $k$. Observations $\mathbf{y}_{k}$ from $M$ different sites are assimilated every time step $k$ (every $3 \mathrm{~h}$ ). Observations and state vector are related by the observation equation

$\mathbf{y}_{k}=\mathbf{H}_{k} \boldsymbol{x}_{k}+\rho_{k}, \quad$ with $\quad \rho_{k} \sim N\left(0, \mathbf{R}_{k}\right)$.

where $\mathbf{H}_{k}$ is the observation operator which projects from the state space onto the observation space. The model-data mismatch $\rho_{k}=\left(\mu_{k}^{2}+\sigma_{k}^{2}\right)^{1 / 2}$ described by the covariance matrix $\mathbf{R}_{k}$ is composed of the measurement errors $\mu_{k}$ and model errors $\sigma_{k}$, the latter describing the uncertainty of the projection $\mathbf{H}_{k}$. The matrix $\mathbf{H}_{k}$ has dimension $M \times N$ with $M$ the number of observations available at time $k$ and $N$ the dimension of the state vector, $N=N^{\mathrm{e}}+N^{\mathrm{b}}+N^{\mathrm{o}}$. Each row of $\mathbf{H}_{k}$ projects the state onto a single observation. If $x$ would be the gridded emissions rather than their logarithms, then the first $N^{\mathrm{e}}$ elements of row $i$ of $\mathbf{H}_{k}$ would simply be the footprint $\mathbf{F}_{k, i}$ (or SRR) of station $i$ at time $k$ calculated by FLEXPART. To ensure positiveness of the estimated emissions, however, we choose $x^{\mathrm{e}}$ to represent the logarithms of the emissions. Equation (6) then becomes non-linear, $\mathbf{y}_{k}=\mathbf{h}_{k}\left(\boldsymbol{x}_{k}\right)+\rho_{k}$, and we need to apply an extended Kalman filter by linearizing $\mathbf{h}_{k}$ around the first guess state $\boldsymbol{x}_{k}^{\mathrm{e}-}$. The operator $\mathbf{h}_{k}$ is non-linear only for the emissions part of the state vector $\boldsymbol{x}_{k}^{\mathrm{e}}$ for which it reads

$\mathbf{h}_{k}^{\mathrm{e}}\left(\boldsymbol{x}_{k}^{\mathrm{e}}\right)=\mathbf{F}_{k} \exp \left(\boldsymbol{x}_{k}^{\mathrm{e}}\right)$.

The linear mapping operator $\mathbf{H}_{k}^{\mathrm{e}}$ is then given by the partial derivatives (Jacobian) of $\mathbf{h}_{k}^{\mathrm{e}}$ which is easily derived from Eq. (7) as

$\mathbf{H}_{k}^{\mathrm{e}}=\mathbf{F}_{k} \exp \left(\boldsymbol{x}_{k}^{\mathrm{e}-}\right)$

for linearization around the first guess $\boldsymbol{x}_{k}^{\mathrm{e}-}$. The remaining elements of row $i$ of $\mathbf{H}_{k}$ are zero except for element $N^{\mathrm{e}}+i$ which adds the background concentration $x_{i, k}^{\mathrm{b}}$ and which therefore is one. An observation value is thus considered to be composed of a background plus the contribution from recent emissions within the time span covered by the FLEXPART simulation.
It is important to notice that in our case the model-data mismatch $\rho_{k}$ in Eq. (6), which is often referred to as the measurement error, is only to a minor extent determined by the true measurement errors $\mu_{k}$ but rather by the errors $\sigma_{k}$ associated with the operator $\mathbf{H}_{k}$ reflecting the uncertainty in the simulated transport and hence in the footprints $\mathbf{F}_{k}$.

By projecting the first guess state $x_{k}^{-}$we obtain a model estimate of the observation values

$\mathbf{y}_{k}^{-}=\mathbf{H}_{k} \boldsymbol{x}_{k}^{-}$

which can be compared with the true observations. In data assimilation, the residuals $\mathbf{v}_{k} \equiv \mathbf{y}_{k}-\mathbf{y}_{k}^{-}$are often referred to as measurement innovations.

The Kalman filter update equation provides the new analysis $\boldsymbol{x}_{k}^{+}$based on the first guess $\boldsymbol{x}_{k}^{-}$and the new observations $\mathbf{y}_{k}$ as

$\boldsymbol{x}_{k}^{+}=\boldsymbol{x}_{k}^{-}+\mathbf{K}_{k}\left(\mathbf{y}_{k}-\mathbf{y}_{k}^{-}\right)$

where $\mathbf{K}_{k}$ is the Kalman gain matrix given by

$\mathbf{K}_{k}=\mathbf{P}_{k}^{-} \mathbf{H}_{k}^{T}\left(\mathbf{R}_{k}+\mathbf{H}_{k} \mathbf{P}_{k}^{-} \mathbf{H}_{k}^{T}\right)^{-1}$.

The assimilation of new observations reduces the error $\mathbf{P}_{k}$ of the state according to

$\mathbf{P}_{k}^{+}=\left(1-\mathbf{K}_{k} \mathbf{H}_{k}\right) \mathbf{P}_{k}^{-}$.

which describes the update of the error analogous to the update of the state in Eq. (10). Equations (4), (5), (10), and (12) together with (9) and (11) form the basic equations of a Kalman filter which are applied sequentially to move the estimate of the state and its error covariance from time $k-1$ to time $k$.

For the Kalman filter to be optimal the residuals $\mathbf{v}_{k}$ need to be uncorrelated in time. However, by applying the above equations we found significant correlations which are most likely due to temporally correlated errors in simulated transport. To deal with this problem we tested a red noise Kalman filter with augmented state as described in Simon (2006, 189-199) but the filter turned out to become numerically unstable. We finally chose the following approach, modifying the observation Eq. (6) to

$\mathbf{y}_{k}=\mathbf{H}_{k} \boldsymbol{x}_{k}+\mathbf{A}_{k} \mathbf{v}_{k-1}+\rho_{k}$

where $\mathbf{A}_{k}$ is a diagonal matrix with diagonal elements $\alpha_{k, i i}$ representing the coefficients of an $\mathrm{AR}(1)$ autoregressive process (one coefficient per station) and $\mathbf{v}_{k-1}$ are the residuals of the previous time step. The state vector is then augmented to include the coefficients $\alpha_{k, i i}$ and the values $\mathbf{v}_{k-1}$ are included in the observation operator $\mathbf{H}_{k}$. The Kalman filter equations above then remain valid. Note that the term $\mathbf{v}_{k-1}$ depends on the previous state $\boldsymbol{x}_{k-1}^{-}$which introduces a non-linearity that we do not account for. In practice, however, this approach turned out to work very well and stably in nearly all cases, and as will be demonstrated in Sect. 3, it clearly outperformed the standard solution not accounting for red noise. 


\subsection{Error covariances and initialization}

Proper setup of the error covariance matrices $\mathbf{Q}_{k}$ and $\mathbf{R}_{k}$ is required for the successful application of the Kalman filter. Our matrices are fully determined by a few parameters which are estimated using a maximum likelihood approach as described in Sect. 2.5. As usual, the matrix $\mathbf{R}_{k}$ is chosen to be diagonal assuming no correlation between errors at the different stations. Note, however, that in the case of a dense measurement network with stations located close to each other it might be necessary to include off-diagonal elements in the design of $\mathbf{R}_{k}$ to account for correlated transport errors. The variance (diagonal element) $r_{k, i i}$ of observation $i$ is calculated as

$\mathbf{r}_{k, i i}=\rho_{\min }^{2}+\left(\rho_{\mathrm{obs}} \cdot y_{k, i}\right)^{2}+\left(\rho_{\mathrm{srr}} \cdot \mathbf{H}_{k, i}^{\mathrm{e}} \boldsymbol{x}_{k}^{\mathrm{e}-}\right)^{2}$

with the three parameters $\rho_{\text {min }}, \rho_{\text {obs }}$, and $\rho_{\text {srr }}$ describing the minimum absolute uncertainty, the relative uncertainty of the measured concentration, and the relative uncertainty of the simulated concentration due to errors in transport (SRR uncertainty), respectively. The minimum uncertainty can be considered as being composed of the instrument detection limit (when $y_{k, i}$ approaches zero) and a minimum uncertainty of the simulated concentration (when the scalar product $\mathbf{H}_{k, i}^{\mathrm{e}} \boldsymbol{x}_{k}^{\mathrm{e}-}$ approaches zero).

The matrix $\mathbf{Q}_{k}$ is a block-diagonal matrix with blocks $\mathbf{Q}_{k}^{\mathrm{e}}$, $\mathbf{Q}^{\mathrm{b}}$, and $\mathbf{Q}^{\mathrm{o}}$ for the different components of the state vector (emissions, background, others). $\mathbf{Q}_{k}^{\mathrm{e}}$ is designed to include off-diagonal elements representing spatial correlations between the errors of neighboring grid cells. The diagonal elements are calculated as

$\mathbf{q}_{k, i i}^{\mathrm{e}}=\eta_{\mathrm{e}}^{2}$

and the off-diagonal elements as

$\mathbf{q}_{k, i j}^{\mathrm{e}}=\eta_{\mathrm{e}}^{2} \cdot e^{-d_{i j} / d_{\mathrm{s}}}$

assuming an exponential decay of the spatial correlation, with $d_{i j}$ the great-circle distance (in kilometers) between the centers of grid cells $i$ and $j$ and $d_{\mathrm{s}}$ the length scale of the correlation, set to $500 \mathrm{~km}$.

The remaining blocks $\mathbf{Q}_{k}^{\mathrm{b}}$ and $\mathbf{Q}_{k}^{\mathrm{o}}$ are diagonal since we do not expect any correlations in the errors of the background, background trend and AR(1) coefficients between the different stations. The corresponding variances are represented by $\eta_{\mathrm{b}}^{2}, \eta_{\mathrm{t}}^{2}$ and $\eta_{\mathrm{a}}^{2}$ analogous to Eq. (15). The parameters $\rho_{\min }$, $\rho_{\text {srr }}, \eta_{\mathrm{e}}, \eta_{\mathrm{b}}$, and $\eta_{\mathrm{t}}$ are estimated by maximum likelihood as described in the next section.

The assimilation starts at time $k=0$ with an initial state vector $\boldsymbol{x}_{0}$ with error covariance $\mathbf{P}_{0}$. In this study we make the pessimistic assumption that no prior information is available and therefore start with a constant (logarithmic) emission field with a constant uncertainty of $200 \%$ and a spatial correlation as described by Eq. (16). Assimilation of observations then slowly draws the solution towards the true emission field. Because the convergence is slow, especially in poorly covered regions, the inversion may be iterated backward and forward several times. The final setup applied in this study includes three iterations, a forward simulation over all available years (currently 2006-2010) to adjust the a priori to a more realistic distribution, followed by a backward and again a forward simulation. The last two simulations are then averaged which has the advantage of removing any time lag generated by the Kalman filter when applied only in one direction. Such a time lag is typical for a Kalman filter which only optimizes for past observations up to the current time $k$. As a result of the iteration, a single observation is assimilated multiple times. This artificially increases the weight of each observation and doing this multiple times would ultimately lead to a noisy solution due to noise amplification. Nevertheless we choose this approach, yet with only three iterations, for the reasons mentioned above. The effect of these iterations on the estimated uncertainties will be discussed in Sect. 4.

A better way to eliminate the time lag would be the use of a Kalman smoother which can account for both past and future observations. However, a Kalman smoother is much more demanding in terms of computing resources and more difficult to implement, but it might be considered in a future implementation.

The background value at each station is initialized as the 10th percentile of the first 100 observations and the background trend is set to 0 . The respective initial uncertainties are set to $0.1 \%$ of the background concentration and to a $0.001 \%$ change of the background concentration per 3 hours. The AR(1) coefficients are initialized with a value of 0.6 which is close to the a posteriori values, and the initial uncertainty is set to 0 .

It is important to note that these initial settings have only a limited influence on the results since with an increasing number of observations assimilated with time the memory for the initialization is gradually lost. Too small initial uncertainties, however, may significantly delay the adjustment to the assimilated information. The sensitivity to the initialization will be analyzed in Sect. 4.1.

\subsection{Parameter estimation by maximum likelihood}

Maximizing the likelihood function is a common method for parameter estimation in Kalman filtering (Harvey, 1989; Simon, 2006; Brunner et al., 2006). For a Kalman filter the log-likelihood is easily obtained as

$\mathrm{LLH}=-0.5 \sum_{k}\left(\ln \left(\operatorname{det}\left(\mathbf{M}_{k}\right)\right)+\mathbf{v}_{k}^{T} \mathbf{M}_{k}^{-1} \mathbf{v}_{k}\right)$

where

$\mathbf{M}_{k}=\mathbf{R}_{k}+\mathbf{H}_{k} \mathbf{P}_{k}^{-} \mathbf{H}_{k}^{T}=\operatorname{Cov}\left(\mathbf{y}_{k}-\mathbf{y}_{k}^{-}\right)$ 
(a)

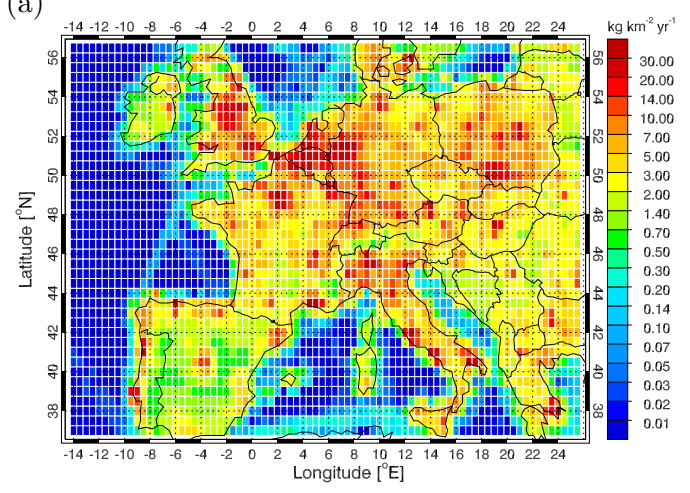

(b)

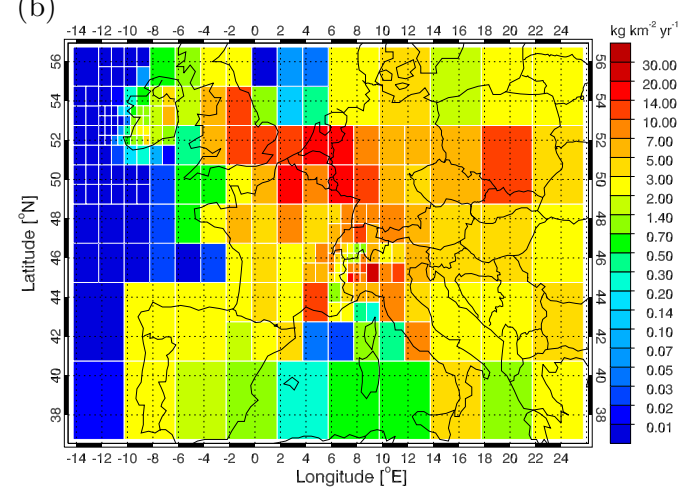

Fig. 3. CO emissions in 2005 according to EMEP/CEIP (http://www.ceip.at/) inventory and reduced by a factor 1000 to match the range of halocarbon emissions. (a) Emissions on regular $0.5^{\circ} \times 0.5^{\circ}$ grid. (b) Emissions on reduced grid with 224 cells used for the inversion.

is the error of the residuals $\mathbf{v}_{k}$ and the sum is over all time steps $k$. Our goal is thus to find the parameter set $\left(\rho_{\min }, \rho_{\text {srr }}\right.$, $\left.\eta_{\mathrm{e}}, \eta_{\mathrm{b}}, \eta_{\mathrm{t}}\right)$ that maximizes LLH. To reduce the dimension of the problem we fixed the parameter $\eta_{\mathrm{a}}$ to $10^{-4}$ and only performed a few sensitivity tests with different values of $\eta_{\mathrm{a}}$. $\rho_{\text {obs }}$ was set to 0.01 assuming a $1 \%$ measurement uncertainty which is close to typical measurement precisions for HFCs and HCFCs (Miller et al., 2008). Finding the maximum of LLH is computationally expensive since it requires numerous inversions with varying parameter sets. We employed Powell's method as described in Press et al. (2007) which approaches the maximum (in fact the minimum of - LLH) by systematically varying the parameters along the gradients of the function in the 5-dimensional parameter space. Optimized parameter sets for the three investigated halocarbons will be presented in Sect. 4.

A limitation of the current setup is that the transport error $\rho_{\text {srr }}$ is optimized over all stations simultaneously. In future studies we will investigate possibilities to better account for the varying ability of the transport model to correctly describe the meteorology at the individual sites while at the same time keeping the optimization problem manageable.

\section{Performance analysis with synthetic observations}

To analyze the performance of the inversion a test setup with pseudo-observations was created. Synthetic time series of trace gas volume mixing ratios were generated for Jungfraujoch and Mace Head by multiplying the EMEP/CEIP CO emission inventory of the year 2005 shown in Fig. 3a with the station footprints and adding different levels of noise (EMEP/CEIP CO emissions were reduced by a factor 1000 to be in the range of typical halocarbon emissions). To reduce the dimension of the problem and to account for the decreasing sensitivity with increasing distance from the observation sites, an irregular inversion grid was created based on the average footprint in Fig. 2 in such a way that the residence
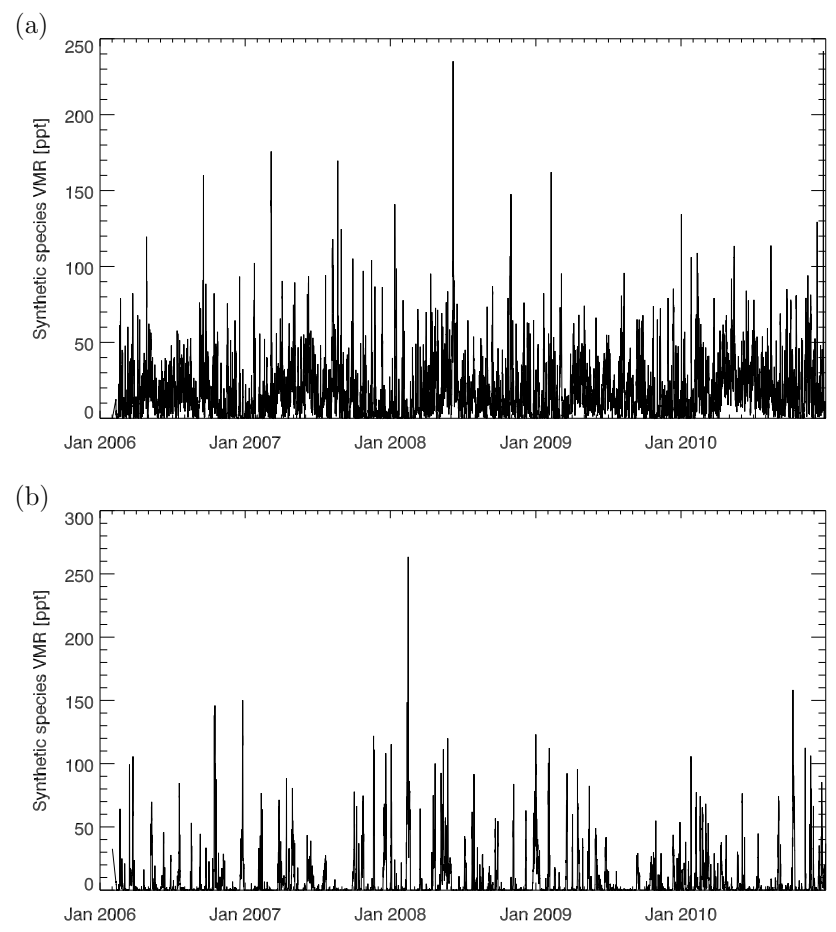

Fig. 4. Time series of the synthetic tracer at Jungfraujoch (a) and Mace Head (b) constructed from the original emission grid.

time in each grid cell is in a similar range. The resolution gradually diminishes from $0.5^{\circ}$ close to the sites to $4^{\circ} \times 4^{\circ}$ in poorly covered regions. Similar reduced grids were used by other authors (Manning et al., 2003; Vollmer et al., 2009; Keller et al., 2011). CO emissions mapped onto this reduced grid are shown in Fig. 3b.

Figure 4 presents the synthetic time series for Jungfraujoch and Mace Head generated from the original grid. The corresponding time series for the reduced grid are nearly identical $\left(r^{2}=0.98\right.$ for Jungfraujoch and 0.99 for Mace Head $)$ indicating that the reduced grid is adequate to reproduce the 
Table 1. Country emissions and aggregation errors introduced by reduced grid. For columns denoted "with sea" the sea fractions of pixels partially over sea and over land are attributed to the surrounding countries proportional to their relative areal share.

\begin{tabular}{lrrrrrr}
\hline Country & \multicolumn{2}{c}{$\begin{array}{c}\text { Original grid } \\
\left(\mathrm{Mg} \mathrm{yr}^{-1}\right)\end{array}$} & \multicolumn{2}{c}{$\begin{array}{c}\text { Reduced grid } \\
\left(\mathrm{Mg} \mathrm{yr}^{-1}\right)\end{array}$} & \multicolumn{2}{c}{$\begin{array}{c}\text { Relative difference } \\
\text { w/ })\end{array}$} \\
& w/o sea & with sea & w/o sea & with sea & w/o sea & with sea \\
\hline Switzerland & 314 & 314 & 356 & 356 & 13.4 & 13.5 \\
Germany & 4084 & 4136 & 3871 & 4188 & -5.2 & 1.3 \\
Italy & 3186 & 3924 & 2349 & 3877 & -26.3 & -1.2 \\
France & 4704 & 5335 & 4362 & 5199 & -7.3 & -2.5 \\
Spain + Portugal & 2371 & 2736 & 1857 & 2841 & -21.7 & 3.8 \\
UK & 1993 & 2383 & 1935 & 2514 & -2.9 & 5.5 \\
Benelux & 1509 & 1636 & 1354 & 1877 & -10.3 & 14.7 \\
Austria & 681 & 681 & 634 & 649 & -6.8 & -4.7 \\
\hline
\end{tabular}

"observed" variability. The figure illustrates the different characteristics of the two stations. At Jungfraujoch there is a rather persistent influence of pollution transport from the European boundary layer with a pronounced seasonal cycle peaking in summer consistent with stronger vertical mixing in this season. On top of this there is a large number of short pollution events throughout the year caused by strong uplift of PBL air probably in organized air streams associated with frontal passages and orographically forced uplift in Föhn situations. At Mace Head there is no persistent European influence visible but again a large number of pollution events caused by synoptic variability alternating between clean air masses from the North Atlantic and polluted air masses from Europe reaching the site.

The coarse resolution of the reduced grid complicates the attribution of emissions to individual countries. The total emission $X_{\mathrm{c}}$ of a country is obtained as the scalar product

$X_{\mathrm{c}}=\mathbf{z}_{\mathrm{c}}^{T} \cdot \exp \left(\mathbf{x}^{\mathrm{e}}\right)$

where $\mathbf{z}_{\mathrm{c}}$ is a country-specific mapping vector of the same dimension $N^{e}$ as the emission field $\exp \left(\mathbf{x}^{\mathrm{e}}\right)$. Each element of $\mathbf{z}_{c}$ represents the fraction of the corresponding grid cell located inside the country. For any given reduced grid, a relative aggregation error can be calculated as $\left(X_{\mathrm{c}}^{\mathrm{red}}-X_{\mathrm{c}}^{\mathrm{ref}}\right) / X_{\mathrm{c}}^{\mathrm{ref}}$ where $X_{\mathrm{c}}^{\mathrm{ref}}$ corresponds to the total country emission obtained with the high resolution (reference) inventory shown in Fig. 3a.

Corresponding aggregation errors are listed in Table 1 for selected countries. For the columns "w/o sea" only the fractions of grid cells covered by land are attributed to individual countries. For countries with long coastlines aggregation errors may become large, up to 20-30\%, particularly in distant regions with large grid cells. These errors can be reduced to mostly well below $10 \%$ when also the sea covered fractions of partial land pixels are attributed to the surrounding countries proportional to their fractional areal coverage (columns denoted "with sea"). All numbers reported in the following therefore include this sea fraction.

\subsection{Noise-free synthetic observations}

A first inversion was performed on the original synthetic time series to test the basic setup. In this noise-free case a correctly configured inversion should be able to fully reconstruct the original field. A constant offset was added to the synthetic concentrations of Fig. 2 to test the ability of the inversion to reproduce not only the emission field but also a (constant) concentration background. Figure 5 shows the evolution of the originally constant emission field (panel a) for different assimilation windows (b-d). After only 1 month of assimilation the distribution already reflects the contrast between land and sea and the main emission region extending from the German Ruhr area to the United Kingdom is beginning to show up. The pattern sharpens in the following months and after $5 \mathrm{yr}$ the field very closely matches the original one $\left(R^{2}=0.97\right.$, RMS reduced by a factor 40 relative to prior) with small differences remaining over poorly observed regions. Differences over the ocean appear prominently in the figure but are small in absolute numbers. In the operational setup the field after $5 \mathrm{yr}$ would serve as a priori for the first of the two iterations finally used. The operational inversion reproduces the reduced-grid country-specific emissions listed in Table 1 to within $2.5 \%$ for all countries.

Figure 6 shows the overall convergence of the solution with time in terms of RMS difference between estimated and original emissions normalized by the a priori RMS. The solid and dashed curves differ by the value assigned to the footprint uncertainty, which is either $80 \%$ (solid lines) or $20 \%$ (dashed lines). The black lines correspond to the noise-free case (perfect observations, perfect model). The red and blue lines represent a more realistic situation with noisy observations as discussed below. In all simulations the RMS drops rapidly during the first few months but the further evolution differs strongly between the noisy and noise-free cases. In the noise-free case a lower footprint uncertainty $\rho_{\text {srr }}$ leads to a more rapid convergence. This is opposite to the case of noisy data as discussed in the next section. 
Table 2. Setup and performance of synthetic simulations. Settings common to all simulations are $\rho_{\min }=6.6 \mathrm{ppt}, \rho_{\mathrm{obs}}=0.01, \eta_{\mathrm{e}}=0.01$, $\eta_{\mathrm{b}}=0.096, \eta_{\mathrm{t}}=0.0019, d_{\mathrm{s}}=500 \mathrm{~km}$. Inversions were performed with regular $\left(\rho_{\mathrm{srr}}=0.8\right)$ or reduced footprint uncertainty $\left(\rho_{\text {srr }}=0.2\right)$ and with or without considering autocorrelation. Synthetic time series were created by adding different levels of Gaussian noise both to the background values ("bgnd", in \% of background level) and to simulated concentrations above background due to European emissions ("emiss") with different levels of autocorrelation $\alpha$ ( $\alpha=0$ for uncorrelated white noise).

\begin{tabular}{|c|c|c|c|c|c|c|c|c|c|c|c|c|c|}
\hline Case & $\begin{array}{l}\text { noise } \\
\text { bgnd }\end{array}$ & $\begin{array}{l}\text { level } \\
\text { emiss }\end{array}$ & $\begin{array}{l}\text { bgnd var } \\
\text { seasonal }\end{array}$ & $\begin{array}{l}\text { ation } \\
\text { trend }\end{array}$ & $\begin{array}{l}\text { emission } \\
\text { variation }\end{array}$ & $\alpha$ & $\rho_{\text {srr }}$ & $\begin{array}{c}\text { red } \\
\text { noise }\end{array}$ & $\mathrm{kg} \mathrm{km}^{-2} \mathrm{yr}^{-1} E_{\mathrm{a}}^{\mathrm{e}}$ & $\mathrm{kg} \mathrm{km}^{-2} \mathrm{yr}^{E_{\mathrm{b}}^{\mathrm{e}}}$ & $1-E_{\mathrm{b}}^{\mathrm{e}} / E_{\mathrm{a}}^{\mathrm{e}}$ & $E_{\mathrm{nb}}^{\mathrm{e}}$ & $\left(r_{\mathrm{b}}^{\mathrm{e}}\right)^{2}$ \\
\hline $1 \mathrm{a}$ & $0 \%$ & $0 \%$ & no & no & no & 0.0 & 0.8 & no & 5.91 & 0.82 & $86.1 \%$ & $13.9 \%$ & 0.98 \\
\hline $1 b$ & $0 \%$ & $0 \%$ & no & no & no & 0.0 & 0.2 & no & 5.91 & 0.24 & $95.9 \%$ & $4.2 \%$ & 1.00 \\
\hline 2 & $0 \%$ & $0 \%$ & yes & yes & no & 0.0 & 0.8 & no & 5.91 & 0.82 & $86.4 \%$ & $14.0 \%$ & 0.98 \\
\hline 3 & $0 \%$ & $0 \%$ & yes & yes & yes & 0.0 & 0.8 & no & 6.50 & 0.95 & $85.4 \%$ & $14.7 \%$ & 0.98 \\
\hline 4 & $2 \%$ & $0 \%$ & yes & yes & yes & 0.0 & 0.8 & no & 6.50 & 1.76 & $72.8 \%$ & $27.4 \%$ & 0.93 \\
\hline 5 & $2 \%$ & $50 \%$ & yes & yes & yes & 0.0 & 0.8 & no & 6.50 & 2.18 & $66.5 \%$ & $33.7 \%$ & 0.89 \\
\hline 6 & $2 \%$ & $50 \%$ & yes & yes & yes & 0.7 & 0.8 & no & 6.50 & 3.22 & $50.4 \%$ & $49.9 \%$ & 0.80 \\
\hline $7 a$ & $2 \%$ & $80 \%$ & yes & yes & yes & 0.7 & 0.8 & no & 6.50 & 4.33 & $33.3 \%$ & $67.1 \%$ & 0.70 \\
\hline $7 b$ & $2 \%$ & $80 \%$ & yes & yes & yes & 0.7 & 0.8 & yes & 6.50 & 3.71 & $42.8 \%$ & $57.5 \%$ & 0.73 \\
\hline $7 \mathrm{c}$ & $2 \%$ & $80 \%$ & yes & yes & yes & 0.7 & 0.2 & yes & 6.50 & 6.36 & $2.1 \%$ & $98.4 \%$ & 0.46 \\
\hline
\end{tabular}

(a) Initial

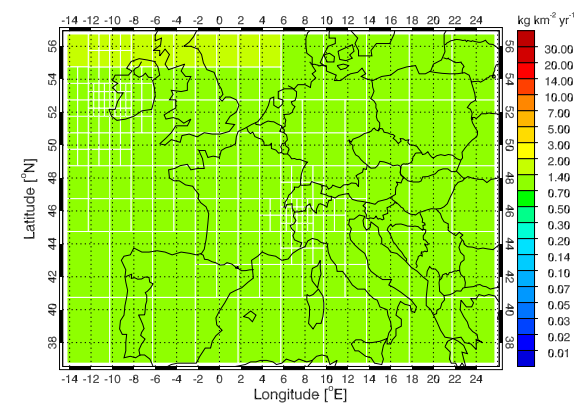

(d) 1 year

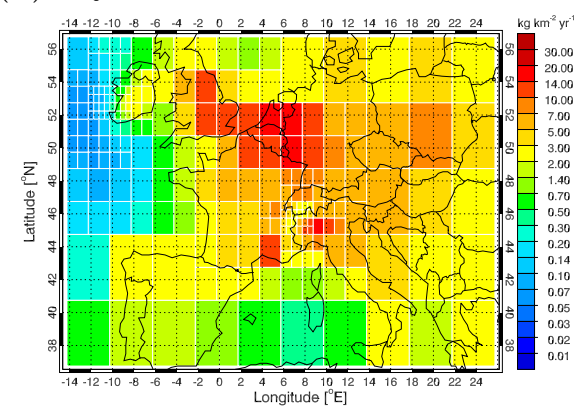

(b) 1 month

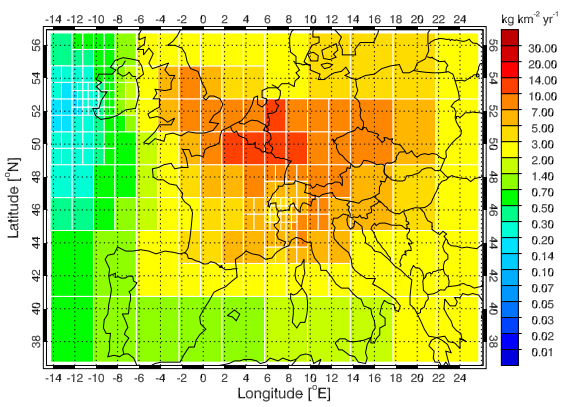

(e) 5 years

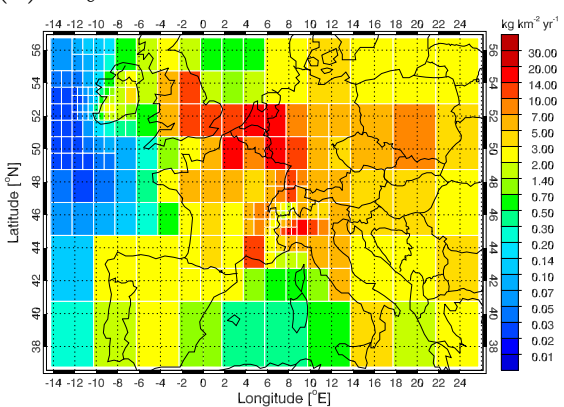

(c) 3 months

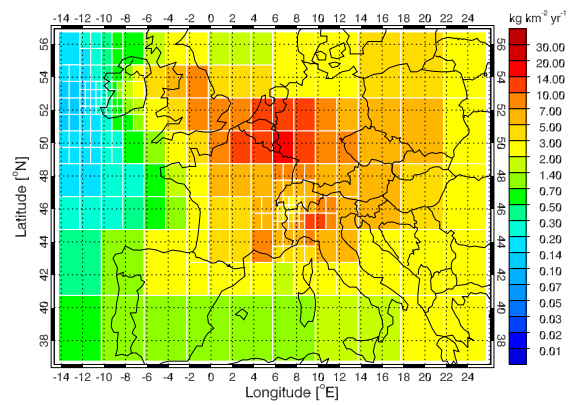

(f) Original

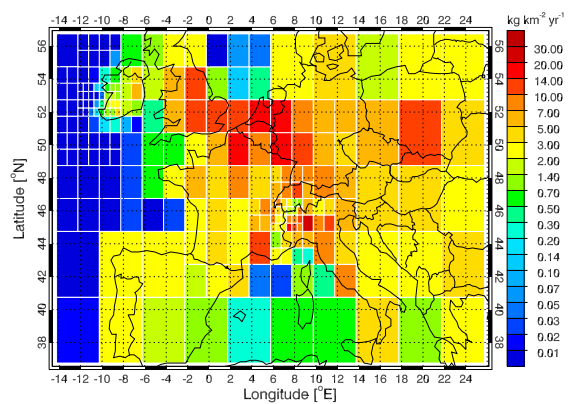

Fig. 5. Evolution of emission field for a simulation with noise-free synthetic observations. The original (true) emission field is shown in panel (f) for reference.

\subsection{Noisy synthetic observations}

In reality, several factors contribute to differences between simulated and measured concentrations including measurement noise and transport model errors. Systematic measurement errors, on the other hand, lead to biases in the estimates but have only little influence on the residuals in our inversion. This is due to the fact that for each station a background is calculated separately, which is different from global inversions which critically depend on accurate background con- centrations and therefore on well inter-calibrated measurements (Rödenbeck et al., 2006). Other sources of error are fluctuations in emissions and background concentrations at time scales not resolved by the inversion. An alternative approach for estimating emissions from strongly varying incidental emissions from known point sources was recently presented and compared with a standard inversion by Keller et al. (2011).

To mimic this situation, we performed a series of inversions with synthetic time series generated by adding different 


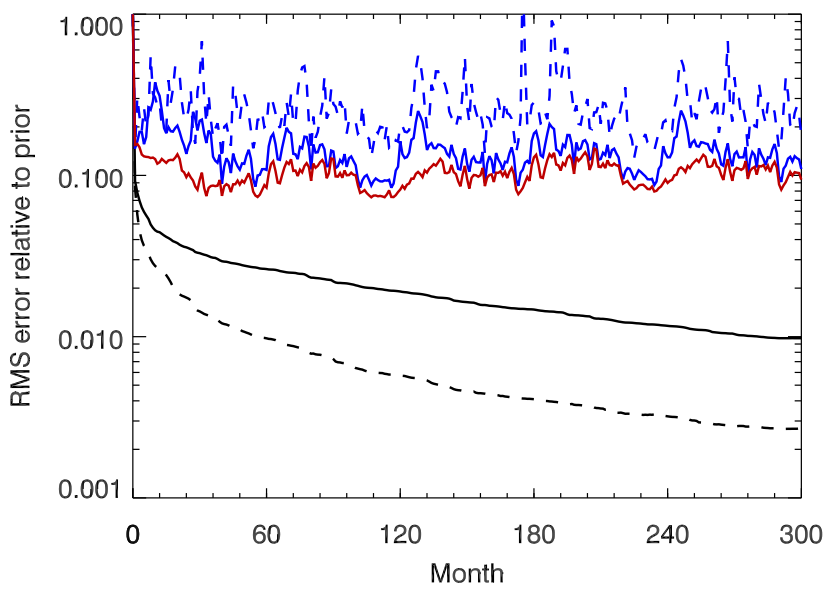

Fig. 6. Evolution of relative RMS error (RMS difference between estimated and true emissions relative to error of prior) for the case of noise free (black) and noisy (color) synthetic observations. Solid lines are for inversions with a transport uncertainty of $\rho_{\text {srr }}=0.8$, dashed lines for a lower uncertainty of $\rho_{\text {srr }}=0.2$. Inversion settings for the noisy case (blue lines) are identical to those for the noise free case (black). The red line is for an inversion identical to the blue solid line but applying the augmented state red-noise Kalman filter.

levels of temporally uncorrelated or correlated noise, by adding seasonally and interannually varying backgrounds, and by scaling the emission field to change linearly from year to year. The setup of these simulations is summarized in Table 2 together with indicators of the performance of the inversion with respect to the true emission field. Corresponding error statistics of simulated versus "observed" concentrations are listed in Table 3 which closely follows the layout of Table 2 in Stohl et al. (2009). The seven cases describe increasingly challenging problems starting from the noisefree case (Case 1) described above for which the RMS error $E_{\mathrm{b}}^{\mathrm{e}}$ is reduced by $86.1 \%$ with respect to the RMS $E_{\mathrm{a}}^{\mathrm{e}}$ of the constant initial field as shown by the term $1-E_{\mathrm{b}}^{\mathrm{e}} / E_{\mathrm{a}}^{\mathrm{e}}$. The RMS error $E_{\mathrm{b}}^{\mathrm{e}}$ of the inverted annual mean emissions is $0.82 \mathrm{~kg} \mathrm{~km}^{-2} \mathrm{yr}^{-1}$, which is $13.9 \%$ of the standard deviation of the original emissions as indicated by the normalized error $E_{\mathrm{nb}}^{\mathrm{e}}$. Note that with additional iterations the error would continue to decrease as shown in Fig. 6 and it is also reduced when assuming a lower uncertainty $\rho_{\text {srr }}$ (Case $1 b$ ).

Cases 2 and 3 are also noise-free but with more challenging variations in background levels (Case 2) and interannually varying emissions (Case 3 ) to test the ability of the inversion to track these changes. For both cases the normalized errors $E_{\mathrm{nb}}^{\mathrm{e}}$ remain close to Case 1 suggesting that such changes can be reproduced accurately. Adding Gaussian white noise of $2 \%$ to the background level mimics a limited measurement precision which roughly doubles the normalized error (Case 4 versus Case 3). Adding Gaussian noise of $50 \%$ to the concentrations above background caused by European emissions (Cases 5 and 6) further increases the error in the a pos- teriori emissions. This increase is substantially larger in the case of correlated noise (Case 6, $\alpha=0.7$ ) as compared to uncorrelated noise (Case 5, $\alpha=0$ ). By judging performance only based on the analysis of simulated versus observed concentrations in Table 3 both cases would appear equal: normalized errors $E_{\mathrm{nb}}^{\mathrm{c}}$ and correlations $r^{2}$ are nearly identical. The only difference is the autocorrelation coefficient $\alpha$ of the residuals, which is essentially zero for Case 5 and about 0.66 for Case 6 indicating that the observations do not provide completely independent information. In Case 7, which is considered to be closest to the real situation, the noise level is enhanced to $80 \%$ which further reduces the quality of the inversion results. Three different inversions were applied for Case 7, the first one like all previous cases without accounting for red noise (Case 7a), the second one using the red-noise Kalman filter with augmented state (7b), and the third one assuming a reduced transport model uncertainty of $\rho_{\text {srr }}=0.2$ (7c). The red-noise Kalman filter (7b) clearly outperforms the simulation without accounting for correlated noise (7a): the normalized error $E_{\mathrm{nb}}^{\mathrm{e}}$ is reduced from $67.1 \%$ to $57.5 \%$ and the correlation $\left(r_{\mathrm{b}}^{\mathrm{e}}\right)^{2}$ is increased from 0.70 to 0.73 . The autocorrelation $\alpha$ of the residuals is effectively reduced to almost zero and simulated and observed time series are highly correlated (see Table 3 ).

In contrast to Case 1 with noise-free data the error in the inverted emissions is strongly enhanced when a too low value $\rho_{\text {srr }}=0.2$ is assumed for the transport model uncertainty (Case 7c) consistent with Fig. 6. In this case the noisy observations receive too much weight in the assimilation which leads to a correspondingly noisy solution. The simulated concentrations follow the observed ones too closely resulting in a high correlation $\left(r_{\mathrm{eb}}^{\mathrm{c}}\right)^{2}$ despite poor performance. Inversion performance can thus not be judged merely based on the observation error statistics in Table 3. Rather, it is important that the different errors assigned to transport, measurements and dynamic model are realistic, or in other words, that the error covariance matrices are adequately representing the true errors and their covariances. This is ensured by the maximum likelihood procedure described in Sect. 2.5.

Finally, we evaluate the ability of the inversion to retrieve country-specific emissions for the countries mentioned earlier. Due to their large distances from Jungfraujoch and Mace Head the countries Spain and Portugal as well as the small countries Belgium, Netherlands and Luxembourg (Benelux) are grouped together. Figure 7 presents the results for the noise-free Case 3 and the realistic Case 7b with correlated noise. In both cases the same linearly changing emissions have been prescribed: a linear increase from 0.8 times the reference emission field shown in Fig. 3b on 1 January 2006 to 1.1 times the reference on 1 January 2009 followed by constant emissions throughout 2009 and 2010. Average emissions in 2006, 2007, and 2008 were thus 0.85, 0.95 and 1.05 times the reference, respectively, and 1.1 times the reference in 2009 and 2010. Figure 7a shows that for Case 3 the values 
Table 3. Error statistics for different inversions from synthetic (cases 1-7) and real observations (cases HFC-125, HFC-152a, HCFC141b). $\bar{y}$ are 2006-2010 mean concentrations, $N$ the number of observations, $E_{\mathrm{a}}^{\mathrm{c}}$ and $E_{\mathrm{b}}^{\mathrm{c}}$ the RMS differences between simulated and observed concentrations for the a priori and a posteriori emissions, respectively, $\alpha$ the 1 st order autocorrelation of the residuals, $E_{\mathrm{nb}}^{\mathrm{c}}$ the a posteriori error normalized by the standard deviation of the observed concentration minus baseline, and $r^{2}$ are the squared Pearson correlation coefficients between a priori minus baseline and observation minus baseline $\left(\left(r_{\mathrm{ea}}^{\mathrm{c}}\right)^{2}\right)$, a posteriori minus baseline and observation minus baseline $\left(\left(r_{\mathrm{eb}}^{\mathrm{c}}\right)^{2}\right)$, and a posteriori versus observation including variations in baseline $\left(\left(r_{\mathrm{b}}^{\mathrm{c}}\right)^{2}\right)$, respectively.

\begin{tabular}{|c|c|c|c|c|c|c|c|c|c|c|c|}
\hline Case & Station & $N$ & $\begin{array}{r}\bar{y} \\
\mathrm{ppt}\end{array}$ & $\begin{array}{c}E_{\mathrm{a}}^{\mathrm{c}} \\
\mathrm{ppt}\end{array}$ & $\begin{array}{c}E_{\mathrm{b}}^{\mathrm{c}} \\
\mathrm{ppt}\end{array}$ & $1-E_{\mathrm{b}}^{\mathrm{c}} / E_{\mathrm{a}}^{\mathrm{c}}$ & $E_{\mathrm{nb}}^{\mathrm{c}}$ & $\alpha$ & $\left(r_{\mathrm{ea}}^{\mathrm{c}}\right)^{2}$ & $\left(r_{\mathrm{eb}}^{\mathrm{c}}\right)^{2}$ & $\left(r_{\mathrm{b}}^{\mathrm{c}}\right)^{2}$ \\
\hline \multirow[t]{2}{*}{$1 \mathrm{a}$} & JFJ & 14280 & 193 & 15.1 & 0.21 & $98.6 \%$ & $1.1 \%$ & 0.66 & 0.85 & 1.00 & 1.00 \\
\hline & MHD & 14280 & 165 & 12.3 & 0.16 & $98.7 \%$ & $1.0 \%$ & 0.72 & 0.46 & 1.00 & 1.00 \\
\hline \multirow[t]{2}{*}{$1 b$} & JFJ & 14280 & 193 & 15.1 & 0.05 & $99.7 \%$ & $0.3 \%$ & 0.60 & 0.85 & 1.00 & 1.00 \\
\hline & MHD & 14280 & 165 & 12.3 & 0.05 & $99.6 \%$ & $0.3 \%$ & 0.66 & 0.46 & 1.00 & 1.00 \\
\hline \multirow[t]{2}{*}{2} & JFJ & 14280 & 211 & 15.2 & 0.27 & $98.2 \%$ & $1.4 \%$ & 0.78 & 0.85 & 1.00 & 1.00 \\
\hline & MHD & 14280 & 181 & 12.3 & 0.17 & $98.6 \%$ & $1.1 \%$ & 0.75 & 0.46 & 1.00 & 1.00 \\
\hline \multirow[t]{2}{*}{3} & JFJ & 14280 & 215 & 15.8 & 0.28 & $98.3 \%$ & $1.4 \%$ & 0.78 & 0.84 & 1.00 & 1.00 \\
\hline & MHD & 14280 & 184 & 12.5 & 0.18 & $98.6 \%$ & $1.1 \%$ & 0.76 & 0.46 & 1.00 & 1.00 \\
\hline \multirow[t]{2}{*}{4} & JFJ & 14280 & 216 & 16.4 & 3.92 & $76.0 \%$ & $19.9 \%$ & 0.02 & 0.81 & 0.96 & 0.98 \\
\hline & MHD & 14280 & 184 & 13.1 & 3.47 & $73.5 \%$ & $21.3 \%$ & 0.01 & 0.44 & 0.95 & 0.98 \\
\hline \multirow[t]{2}{*}{5} & JFJ & 14280 & 216 & 21.0 & 13.4 & $36.1 \%$ & $56.6 \%$ & 0.01 & 0.55 & 0.68 & 0.81 \\
\hline & MHD & 14280 & 185 & 15.9 & 9.07 & $43.0 \%$ & $48.4 \%$ & 0.00 & 0.34 & 0.77 & 0.89 \\
\hline \multirow[t]{2}{*}{6} & JFJ & 14280 & 216 & 21.1 & 13.4 & $36.6 \%$ & $56.4 \%$ & 0.66 & 0.53 & 0.68 & 0.82 \\
\hline & MHD & 14280 & 185 & 16.5 & 8.9 & $46.0 \%$ & $46.1 \%$ & 0.66 & 0.34 & 0.79 & 0.89 \\
\hline \multirow[t]{2}{*}{$7 a$} & JFJ & 14280 & 216 & 26.9 & 20.8 & $22.7 \%$ & $71.8 \%$ & 0.66 & 0.33 & 0.48 & 0.66 \\
\hline & MHD & 14280 & 185 & 20.3 & 13.6 & $32.7 \%$ & $60.1 \%$ & 0.66 & 0.26 & 0.64 & 0.79 \\
\hline \multirow[t]{2}{*}{$7 b$} & JFJ & 14280 & 216 & 27.0 & 14.9 & $44.9 \%$ & $51.3 \%$ & 0.19 & 0.33 & 0.75 & 0.83 \\
\hline & MHD & 14280 & 185 & 20.3 & 9.0 & $55.4 \%$ & $39.8 \%$ & 0.00 & 0.26 & 0.85 & 0.91 \\
\hline \multirow[t]{2}{*}{$7 c$} & $\mathrm{JFJ}$ & 14280 & 216 & 27.0 & 12.9 & $51.9 \%$ & $44.7 \%$ & 0.04 & 0.33 & 0.81 & 0.87 \\
\hline & MHD & 14280 & 185 & 20.2 & 8.2 & $59.6 \%$ & $36.1 \%$ & 0.00 & 0.26 & 0.87 & 0.93 \\
\hline \multirow[t]{2}{*}{ HFC-125 } & JFJ & 8606 & 8.1 & 0.94 & 0.53 & $43.9 \%$ & $56.0 \%$ & 0.07 & 0.31 & 0.69 & 0.91 \\
\hline & MHD & 10420 & 7.5 & 1.20 & 0.61 & $49.3 \%$ & $50.5 \%$ & 0.11 & 0.29 & 0.75 & 0.91 \\
\hline \multirow[t]{2}{*}{ HFC-152a } & JFJ & 9106 & 9.4 & 1.61 & 0.90 & $44.1 \%$ & $55.6 \%$ & 0.01 & 0.19 & 0.69 & 0.81 \\
\hline & MHD & 8604 & 8.7 & 0.65 & 0.33 & $49.4 \%$ & $49.5 \%$ & 0.00 & 0.17 & 0.76 & 0.94 \\
\hline \multirow[t]{2}{*}{ HCFC-141b } & JFJ & 8522 & 21.7 & 0.84 & 0.61 & $27.3 \%$ & $72.6 \%$ & 0.00 & 0.06 & 0.48 & 0.69 \\
\hline & MHD & 10222 & 21.0 & 0.32 & 0.19 & $40.3 \%$ & $58.9 \%$ & 0.05 & 0.24 & 0.66 & 0.96 \\
\hline
\end{tabular}

Table 4. Optimized parameter settings for HFC-125, HFC-152a and HCFC-141b.

\begin{tabular}{llccc}
\hline Parameter & Description & HFC-125 & HFC-152a & HCFC-141b \\
\hline$\rho_{\text {obs }}$ & Relative measurement uncertainty & 0.01 & 0.01 & 0.01 \\
$\rho_{\text {min }}$ & Minimum model-data mismatch $(\mathrm{ppt})$ & 0.20 & 0.38 & 0.43 \\
$\rho_{\mathrm{SRR}}$ & Relative footprint uncertainty & 0.78 & 0.69 & 0.64 \\
$\eta_{\mathrm{e}}$ & Emission prediction error $(\% / 3 \mathrm{~h})$ & 0.30 & 0.81 & 1.95 \\
$\eta_{\mathrm{b}}$ & Background prediction error $(\mathrm{ppt} / 3 \mathrm{~h})$ & $4.88 \times 10^{-3}$ & $0.070^{\mathrm{a}}$ & $6.69 \times 10^{-3}$ \\
$\eta_{\mathrm{t}}$ & B'ground trend pred. error $\left(\mathrm{ppt} /(3 \mathrm{~h})^{2}\right)$ & $9.46 \times 10^{-5}$ & $6.68 \times 10^{-8}$ & $1.00 \times 10^{-6}$ \\
$\eta_{a}$ & AR(1) coefficient prediction error $(1 / 3 \mathrm{~h})$ & $10^{-4}$ & $10^{-4}$ & $10^{-4}$ \\
$d_{\mathrm{S}}$ & Correlation length $(\mathrm{km})$ & 500 & 500 & 500 \\
\hline
\end{tabular}

a Value 3 times lower than optimized value of 0.189.

and interannual differences are almost perfectly matched for all countries and that the error bars provided by the inversion are much too pessimistic. For Case $7 b$ the country averages are still matched quite accurately but year-to-year differences are much less well captured. The lowest emissions are estimated for 2006 for all countries consistent with the pre- scribed emission trend but emissions estimated for 2009 or 2010 are occasionally below the values in 2008 or even 2007 which in fact should be $5 \%$ and $14 \%$ lower, respectively. However, differences are mostly within the indicated $1 \sigma$ uncertainty (and are all within $2 \sigma$ ). In summary, the inversion reproduces the country-specific emissions for Case $7 \mathrm{~b}$ 
(a)

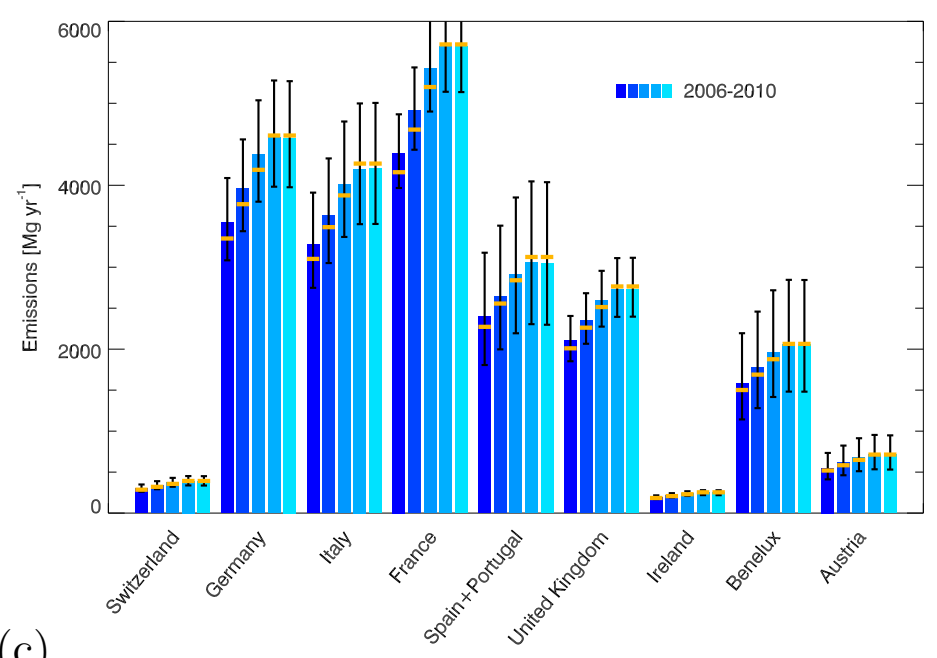

(c)

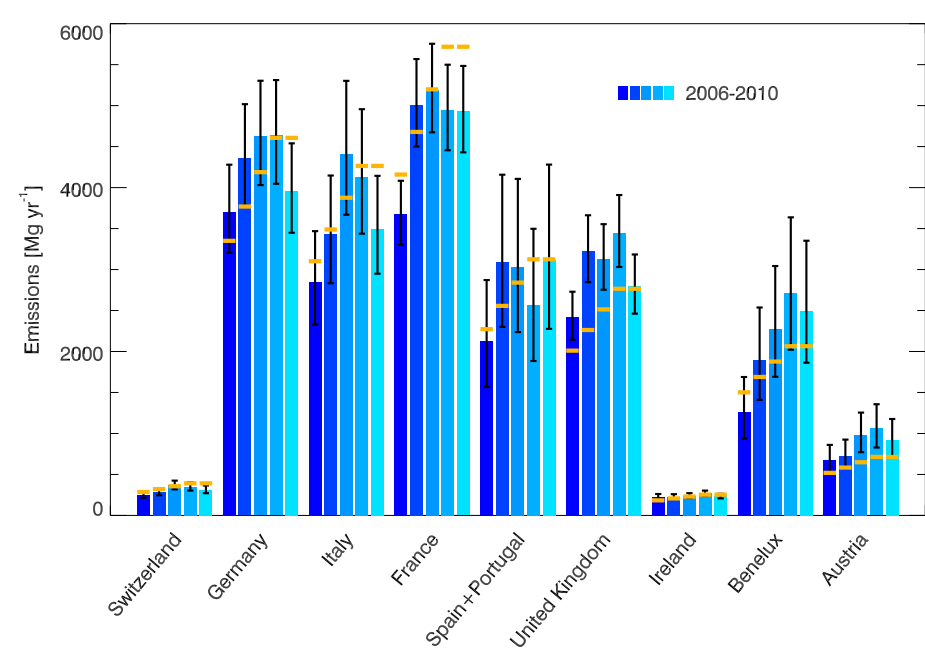

(b)

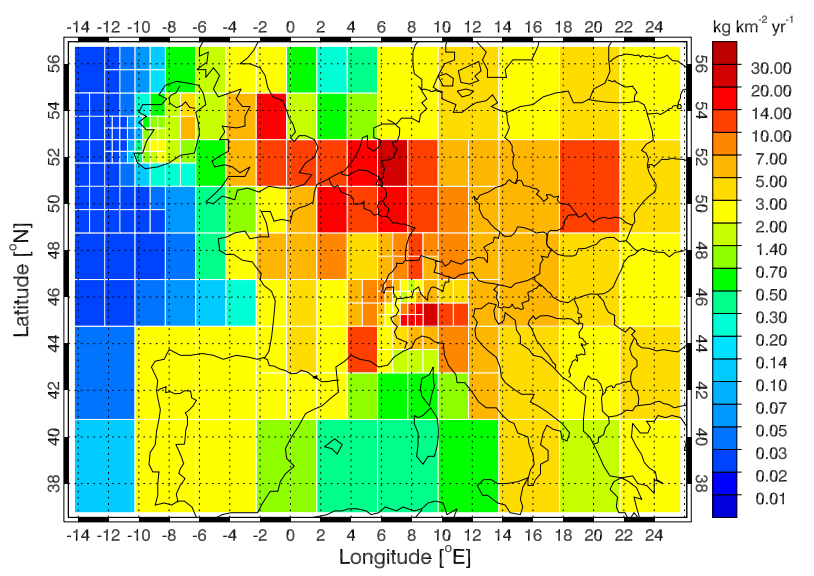

(d)

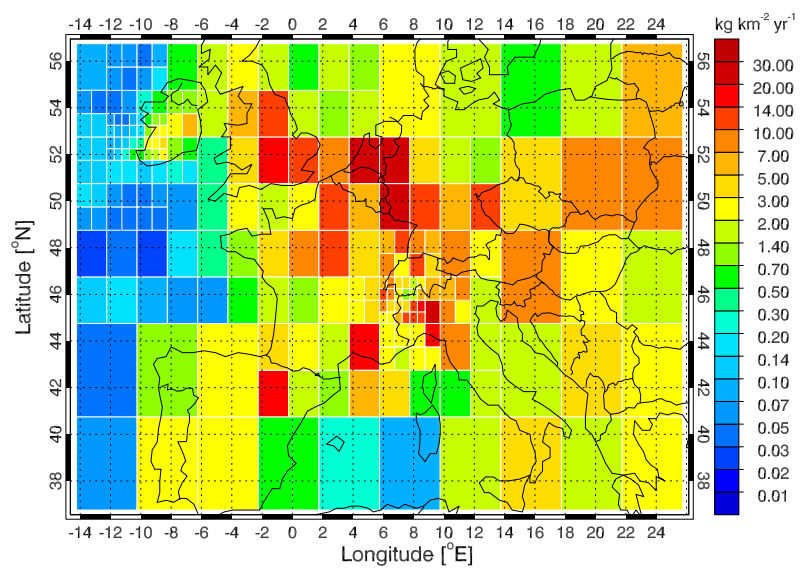

Fig. 7. Emission inversion results for noise-free Case 3 (upper panels (a) and (b)) and noisy Case 7b (lower panels (c) and (d)). Panels (a) and (c) represent annual mean emissions (2006-2010) estimated for selected countries. Blue bars are country-mean a posteriori emissions estimated by the Kalman filter together with their $1 \sigma$ uncertainties. True reference emissions are overlaid as orange horizontal bars. Panels (b) and (d) are annual mean emission maps for the year 2010.

to within about $15-20 \%$ and interannual differences larger than this can be reproduced successfully.

\section{European emissions of HFC-125, HFC-152a and HCFC-141b}

This section presents the results of the inversion method applied to real observations of three different halocarbons measured at Jungfraujoch and Mace Head, an analysis of the sensitivity of the results to different inversion settings, and a comparison with results obtained with the established method of Stohl et al. (2009).

In order to demonstrate the effect of the three iterations applied (see also Sect. 2.4) on the estimated uncertainties,
Fig. 8 shows the evolution of the mean relative uncertainty of the HFC-125 emissions. The simulation starts with a uniform a-priori uncertainty of $200 \%$. After the first iteration, i.e. after assimilating the observations of the period 2006 2010 for the first time, the average uncertainty is reduced to about $62 \%$. During the second iteration it is slightly reduced further to $58 \%$ but remains constant thereafter, indicating that the uncertainty has essentially reached an equilibrium level already after the first iteration. Using the same observations repeatedly does thus not lead to unrealistically low uncertainties because in equilibrium the error reduction due to the assimilation step (Eq. 12) is exactly compensated by the error increase due to the state prediction (Eq. 5). 


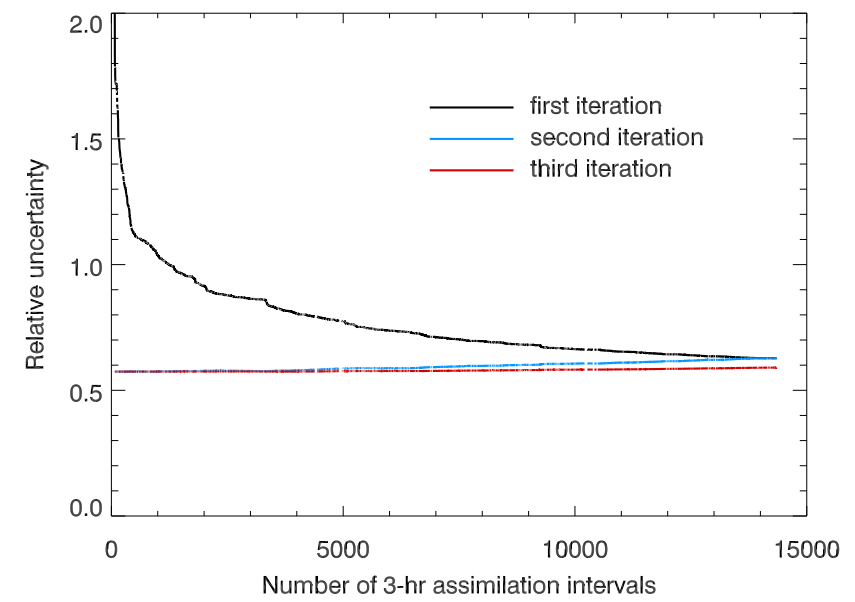

Fig. 8. Evolution of the grid average relative uncertainty of HFC125 emissions for the reference simulation during the three iteration steps. The average uncertainty is calculated as $\sqrt{\operatorname{trace}\left(\mathbf{P}_{k}\right) / N^{\mathrm{e}}}$. The $\mathrm{x}$-axis is the number of 3-h assimilation intervals and covers the full period 2006-2010.

As an example for the quality of the simulations, Fig. 9 compares the observed time series of HFC-125 at Jungfraujoch and Mace Head (black lines) with the corresponding time series simulated by the Kalman filter (red). The dark blue line is the smooth background determined by the filter. The right-hand panels further illustrate the excellent agreement by zooming into a selected period (1 November 2009-15 February 2010). Note that despite the positivedefiniteness of the estimated emissions, the red line can extend below the background, which is a result of the $\operatorname{AR}(1)$ term in Eq. (13). Without considering this term, the correlation between observed and simulated time series (w/o background) is lower, $r=0.65$ instead of 0.83 at JFJ, and $r=0.75$ instead of 0.87 at MHD. When including both the $\mathrm{AR}(1)$ term and the background concentrations, the correlations between simulated and measured concentrations ( $r$ with bgnd) are increased to 0.95 for both Jungfraujoch and Mace Head since a considerable fraction of the observed variance is due to the long-term increase which can easily be traced by the inversion.

Figure 10 presents maps of 2009 annual mean emissions (average of all fields estimated for time steps between January 2009 and December 2009 in units of $\mathrm{kg} \mathrm{km}^{-2} \mathrm{yr}^{-1}$ ) and corresponding $1 \sigma$ uncertainties. These results were obtained with the parameter settings listed in Table 4 obtained with the optimization procedure described in Sect. 2.5. The three species show distinctly different spatial distributions. Emissions of HFC-125 are rather uniformly distributed over Europe with local hot spots in Italy, Germany, the Benelux countries and UK. Emissions in Eastern Europe are comparatively low, particularly in the southeastern domain. Expectedly low emissions over the Atlantic are successfully reproduced and the shape of the coastlines is well followed.
Uncertainties are lower than the estimated emissions in high emission areas but often in the range of the means in low emission regions. Note that due to the estimation of the logarithm of emissions the model calculates relative (multiplicative) rather than absolute uncertainties. These were here simply converted to absolute uncertainties by multiplication with the mean. For an emission of $10 \mathrm{~kg} \mathrm{~km}^{-2} \mathrm{yr}^{-1}$, for example, an uncertainty of $100 \%$ in fact would mean that the emissions could be twice as high (i.e. $20 \mathrm{~kg} \mathrm{~km}^{-2} \mathrm{yr}^{-1}$ ) or twice as low (i.e. $5 \mathrm{~kg} \mathrm{~km}^{-2} \mathrm{yr}^{-1}$ ) but not zero. Absolute uncertainties are thus not symmetric about the mean.

In comparison to HFC-125, HFC-152a emissions are quite low in Germany and very low in Spain, Portugal, UK and Ireland. Highest emissions are clearly identified in Northern Italy but also the Benelux countries and France show significant emission levels. Finally, HCFC-141b, which is controlled by the Montreal Protocol and exhibits strongly decreasing emissions in Europe since about 2003 (Derwent et al., 2007), shows pronounced hot spots in Italy and in France whereas emissions in most other countries are low (note the different color scale used for HCFC-141b). France is known to have been the main producing country of HCFC$141 \mathrm{~b}$ in Europe. The large emissions from France are likely related to $\mathrm{HCFC}-141 \mathrm{~b}$ release from these production plants for which a-priori emissions were not available. Emission uncertainties for HFC-141b are much larger than for the other two species often exceeding $100 \%$.

The improved agreement between simulated and measured concentrations achieved by the inversion is documented in the lower part of Table 3. RMS differences are reduced by $27-49 \%$ as compared to the a priori time series and correlations are strongly enhanced. The best performance was obtained for HFC-125 and HFC-152a while the concentrations of HCFC-141b were more difficult to reproduce.

A problem specific to HFC-152a was the fact that the loglikelihood optimization assigned a large uncertainty to its background concentrations with the consequence that the assimilation more willingly adjusted the background than the emissions. This lead to a highly variable background closely tracking the observations whereas the emission signals and hence the estimated emissions remained small, probably too small. Figure 1b shows that for HFC-152a the baseline is in fact quite variable and, different from the other two species, exhibits a pronounced seasonal cycle. The measurements at Jungfraujoch exhibit many negative excursions below the baseline (and below Mace Head background levels) which are not instrumental artifacts but reflect true variability. A preliminary analysis indicates that these "depletion events" are associated with advection from low latitudes (particularly at Mace Head), and from the upper troposphere or stratosphere (particularly at Jungfraujoch). HFC-152a has a strong north-south gradient due to its comparatively short lifetime $(\sim 1.5 \mathrm{yr})$ and dominant sources in the Northern Hemisphere and probably has significant vertical gradients. Air masses originating from low latitudes are therefore associated with 
(a)

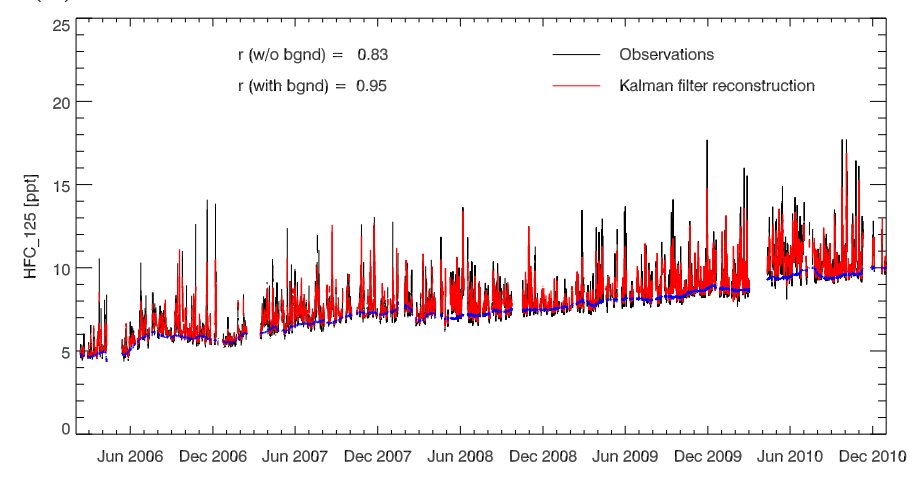

(c)

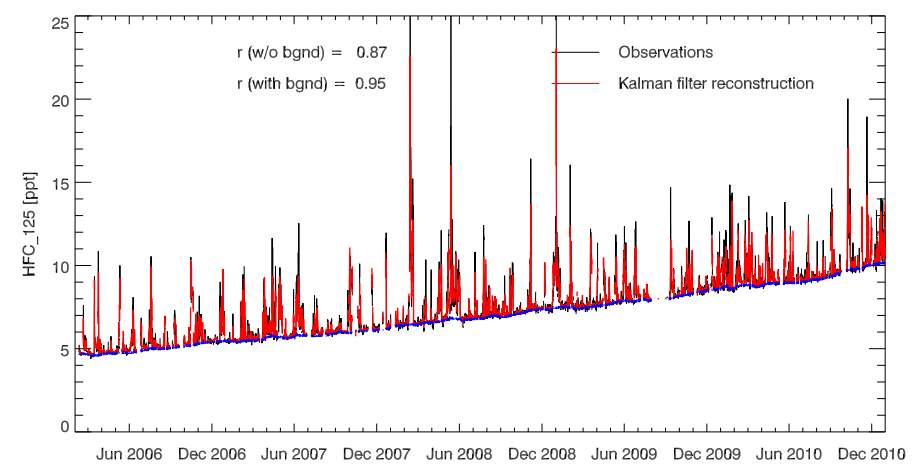

(b)

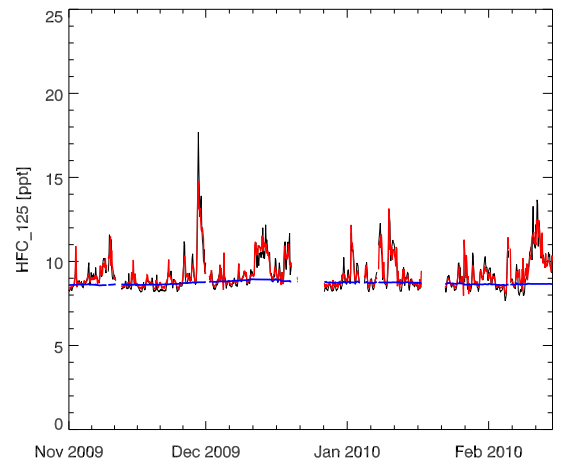

(d)

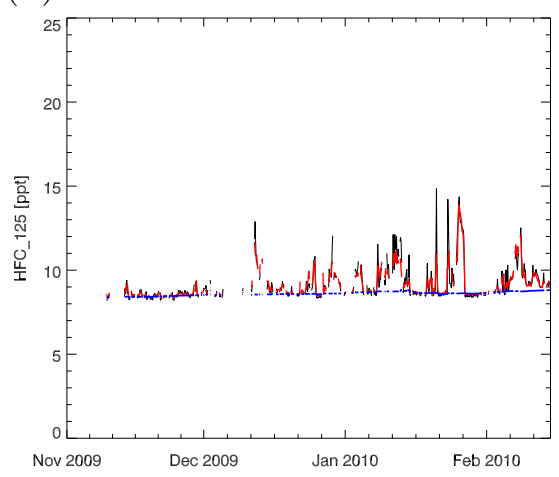

Fig. 9. Comparison of observed (black) and simulated (red) time series at (a),(b) Jungfraujoch and (c),(d) Mace Head from 2006 to 2010. Dark blue lines are smooth backgrounds estimated by the Kalman filter. The panels to the right present a zoom on the period 1 November 2009-15 February 2010.

lower background values than air masses from high latitudes. The inversion tries to reproduce this variability by assigning a large uncertainty to the background. In future inversions of HFC-152a it would therefore be desirable to explicitly account for the influence of advection from different regions on background fluctuations. As a preliminary solution we reduced the background uncertainty by a factor of three which leads to a smoother background and in turn to higher emissions: European emissions are on average enhanced by about $20 \%$ suggesting that the treatment of the background variability represents a major uncertainty in our HFC-152a emission estimates.

The evolution of country-averaged emissions of HFC-125, HFC-152a and HCFC-141b over the five years 2006-2010 is displayed in Fig. 11. Red columns correspond to emissions in 2009 reported to UNFCCC (2011 downloads, available only for HFC-125 and HFC-152a), which can be compared with the second to last column in each group of blue columns representing our estimates. Orange bars are emissions reported for the year 2006. A quantitative summary of all values for the years 2006 and 2009 is provided in Table 5 .

For Germany, France, the UK and the Benelux countries our estimates for HFC-125 are close (within $21 \%$ ) to the values reported to UNFCCC for both 2006 and 2009. All coun- tries except Ireland reported increasing emissions of HFC125 between 2006 and 2009 which agrees well with the estimated changes. Italy reports a very large increase by $42 \%$ from 2006 to 2009 which is larger than our estimated increase of $24 \pm 19 \%$. Reported (estimated) changes for Germany, France, UK and Benelux are 9\% (16士19\%), $26 \%$ $(11 \pm 13 \%), 10 \%(9 \pm 13 \%)$, and $29 \%(5 \pm 22 \%)$ suggesting that increases in Italy, France and Benelux were somewhat smaller than reported. However, given the large uncertainties in the annual values these differences are only marginally significant. Overall, the reported and estimated changes are in reasonable agreement.

Larger discrepancies between reported and estimated emissions are obtained for Italy, Switzerland, Ireland, Spain + Portugal, and Austria. Despite its vicinity to Jungfraujoch, an accurate assessment of Swiss emissions is difficult due to the small area of the country. In addition, the transport model used is scarcely sufficient to resolve the processes responsible for uplift of air from the Swiss Plateau to Jungfraujoch which is often associated with complex thermally-induced wind systems and convective boundary layers over the Alpine topography. Similar arguments also hold for Austria. The large discrepancy for Ireland with $187 \%$ to $312 \%$ higher emissions obtained by the inversion, 
(a) HFC-125 a posteriori emissions

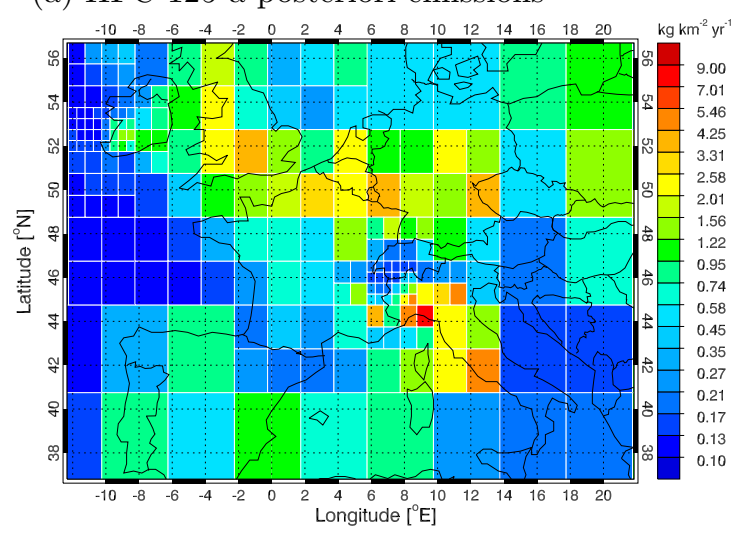

(c) HFC-152a a posteriori emissions

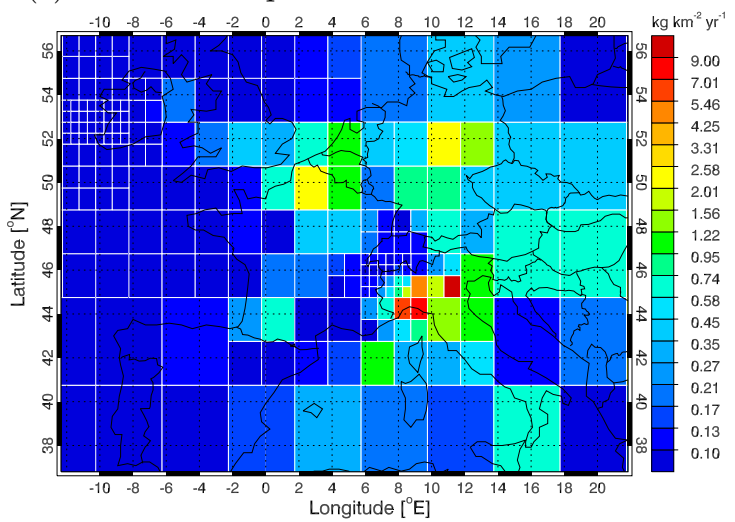

(e) HCFC-141b a posteriori emissions

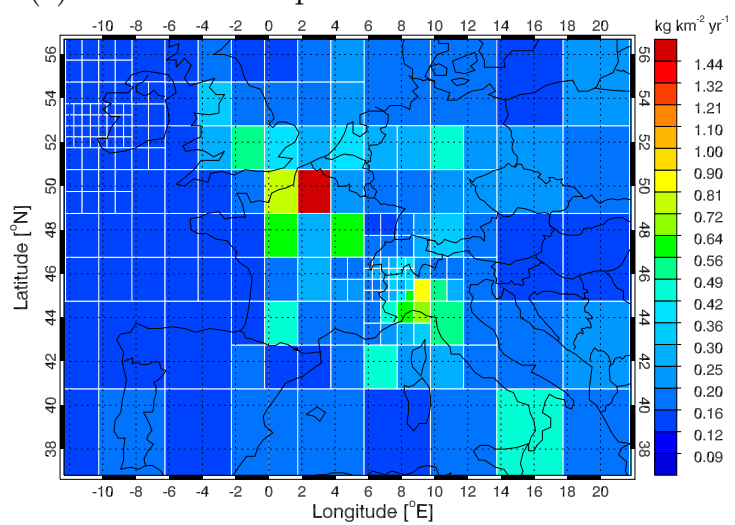

(b) HFC-125 uncertainty

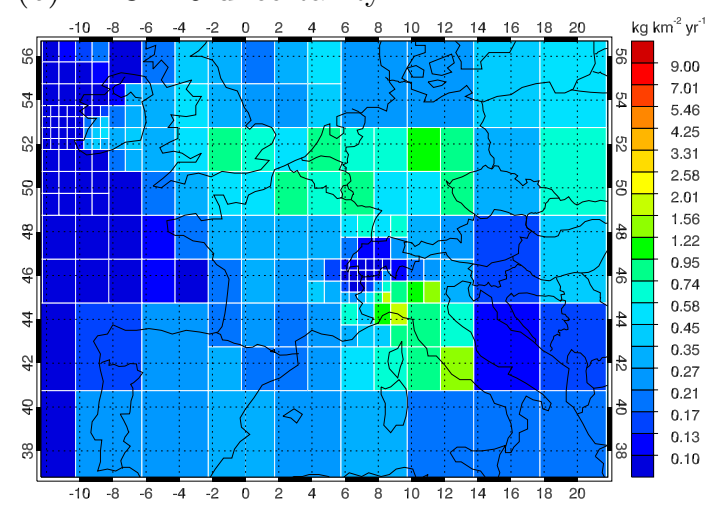

(d) HFC-152a uncertainty

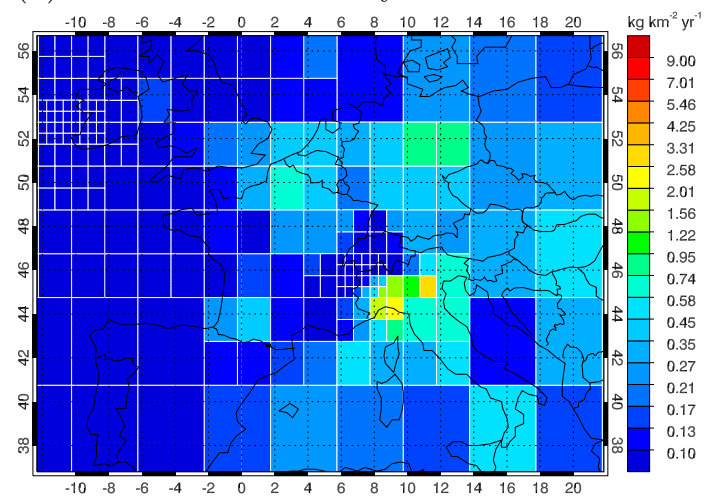

(f) HCFC-141b uncertainty

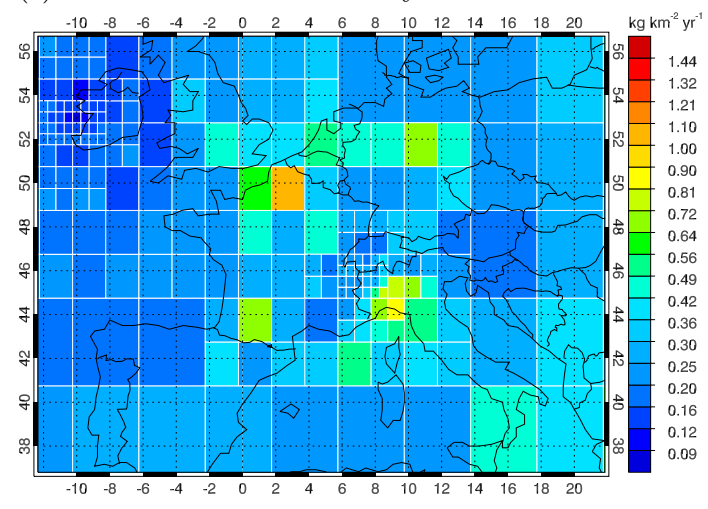

Fig. 10. Distribution of annual mean emissions (left) and their uncertainties (right) of HFC-125, HFC-152a and HCFC-141 in Europe in 2009.

on the other hand, is surprising. Our estimates are in good agreement with a recent British study which also estimated much larger than reported HFC-125 emissions from Ireland of $69 \mathrm{Mg} \mathrm{yr}^{-1}$ in 2006 and $80 \mathrm{Mg} \mathrm{yr}^{-1}$ in 2009 , respectively (O’Doherty et al., 2011).

Figure 1a displays several large HFC-125 peaks which are likely due to the effect of nearby emissions in conjunction with low-wind speeds. Situations with low-winds and low boundary layer heights with correspondingly large sensitivi- ties for local emissions were therefore filtered out in the inversion studies of Manning et al. (2003) and Manning et al. (2011). Excluding these peaks, however, has a negligible impact on our results (e.g. reducing the 2009 value from 84 to $83 \mathrm{Mg} \mathrm{yr}^{-1}$ ) suggesting that local effects are insufficient to explain the discrepancy. A large and significant discrepancy also exists for Spain + Portugal with estimated emissions being $150-170 \%$ higher than the reported numbers. However, these results should be considered with care since the two 
Table 5. Estimated country-specific emissions of HFC-125, HFC-152a and HCFC-141b. For HFC-125 and HFC-152a the UNFCCC bottomup values are also provided for comparison. Although the inversion provides relative uncertainties due to the estimation of the logarithm of emissions, uncertainties are indicated as absolute errors $(1 \sigma)$ by multiplying the estimated emission by its relative uncertainty. For the total of all 12 countries the uncertainty was estimated as the mean squared error.

\begin{tabular}{lcrrrrrrrrrr}
\hline Country & Year & \multicolumn{4}{c}{$\begin{array}{c}\text { HFC-125 } \\
\text { a posteriori } \\
\left(\mathrm{Mg} \mathrm{yr}^{-1}\right)\end{array}$} & $\begin{array}{r}\text { UNFCC } \\
\left(\mathrm{Mg} \mathrm{yr}^{-1}\right)\end{array}$ & $\begin{array}{r}\text { diff. } \\
(\%)\end{array}$ & $\begin{array}{r}\text { a posteriori } \\
\left(\mathrm{Mg} \mathrm{yr}^{-1}\right)\end{array}$ & $\begin{array}{r}\text { UNFCCCC } \\
\left(\mathrm{Mg} \mathrm{yr}^{-1}\right)\end{array}$ & $\begin{array}{r}\text { diff. } \\
(\%)\end{array}$ & $\begin{array}{r}\text { HCFC-141b } \\
\text { a posteriori } \\
\left(\mathrm{Mg} \mathrm{yr}^{-1}\right)\end{array}$ \\
\hline Switzerland & 2006 & 11 & \pm 2 & 63 & -81.5 & 9 & \pm 2 & 15 & -38.7 & 21 & \pm 6 \\
Switzerland & 2009 & 13 & \pm 2 & 75 & -82.0 & 6 & \pm 1 & 1 & 482.6 & 11 & \pm 4 \\
Germany & 2006 & 589 & \pm 69 & 594 & -0.8 & 457 & \pm 82 & 449 & 1.9 & 200 & \pm 82 \\
Germany & 2009 & 683 & \pm 80 & 647 & 5.6 & 351 & \pm 62 & 782 & -55.0 & 119 & \pm 47 \\
Italy & 2006 & 936 & \pm 100 & 691 & 35.5 & 729 & \pm 139 & NA & NA & 451 & \pm 170 \\
Italy & 2009 & 1158 & \pm 128 & 983 & 17.8 & 803 & \pm 135 & $\mathrm{NA}$ & $\mathrm{NA}$ & 269 & \pm 116 \\
France & 2006 & 731 & \pm 61 & 814 & -10.3 & 331 & \pm 45 & 313 & 5.8 & 768 & \pm 257 \\
France & 2009 & 812 & \pm 67 & 1032 & -21.3 & 324 & \pm 47 & 388 & -16.5 & 276 & \pm 67 \\
Spain+Portugal & 2006 & 689 & \pm 88 & 252 & 173.1 & 225 & \pm 71 & 413 & -45.5 & 238 & \pm 114 \\
Spain+Portugal & 2009 & 861 & \pm 111 & 341 & 152.0 & 171 & \pm 63 & 354 & -51.6 & 208 & \pm 101 \\
United Kingdom & 2006 & 611 & \pm 53 & 710 & -13.8 & 59 & \pm 14 & 166 & -64.0 & 131 & \pm 40 \\
United Kingdom & 2009 & 665 & \pm 57 & 783 & -15.1 & 68 & \pm 16 & 114 & -40.4 & 108 & \pm 33 \\
Ireland & 2006 & 78 & \pm 7 & 27 & 187.4 & 12 & \pm 2 & 6 & 84.3 & 23 & \pm 6 \\
Ireland & 2009 & 84 & \pm 7 & 20 & 312.1 & 13 & \pm 2 & 7 & 80.6 & 20 & \pm 5 \\
Benelux & 2006 & 223 & \pm 33 & 219 & 2.1 & 80 & \pm 16 & 211 & -61.8 & 41 & \pm 20 \\
Benelux & 2009 & 235 & \pm 34 & 283 & -17.0 & 90 & \pm 18 & 349 & -74.1 & 43 & \pm 22 \\
Austria & 2006 & 32 & \pm 10 & 67 & -51.9 & 57 & \pm 20 & 249 & -76.9 & 44 & \pm 36 \\
Austria & 2009 & 39 & \pm 12 & 79 & -50.5 & 59 & \pm 23 & 130 & -54.1 & 18 & \pm 12 \\
Total 12 countries & 2006 & 3905 & \pm 174 & 3412 & 14.4 & 1965 & \pm 185 & 1818 & 8.1 & 1919 & \pm 344 \\
Total 12 countries & 2009 & 4555 & \pm 210 & 4227 & 7.8 & 1889 & \pm 172 & 2121 & -10.9 & 1077 & \pm 180 \\
\hline
\end{tabular}

observation sites are only weakly sensitive to emissions from Spain and Portugal.

Total emissions summed over the 12 countries are only 8$14 \%$ higher than the UNFCCC bottom-up estimates. The total of $3905 \mathrm{Mg} \mathrm{yr}^{-1}$ for the year 2006 agrees very favorably with the $3800 \mathrm{Mg} \mathrm{yr}^{-1}$ and $4700 \mathrm{Mg} \mathrm{yr}^{-1}$ estimated by O'Doherty et al. (2009) for the EU-15 region using a CO interspecies correlation technique and the NAME model, respectively. The EU-15 region includes the same 12 countries minus Switzerland plus Denmark, Sweden, Finland and Greece. Based on UNFCCC values, EU-15 emissions can be expected to be higher than the total of our 12 countries by only about $174 \mathrm{Mg} \mathrm{yr}^{-1}$.

Results for HFC-152a are less consistent with UNFCCC numbers for individual countries both regarding the magnitude of emissions and their trends. Italy does not report HFC-152a emissions to the UNFCCC. Our results, however, suggest Italy to have the largest emissions in the study area. Emissions reported by Germany very closely match our estimate in 2006 but are much higher in 2009 due to opposing trends. Spain + Portugal report larger emissions of HFC152a than of HFC-125 in strong contrast to our estimates suggesting that HFC-152a emissions are about 3-5 times lower than those of HFC-125. For UK our estimates are 40$60 \%$ lower than the official numbers and while UK reports a marked decrease from 2006 to 2009 our results suggest a small increase. Emissions reported by France are broadly consistent with our estimates, whereas those reported by the Benelux countries are at least a factor of 2.6-3.9 higher than our top-down values. The total over all 12 countries is consistent with the bottom-up estimates with $8 \%$ higher values than UNFCCC in 2006 and $11 \%$ lower values in 2009 suggesting that non-reported emissions from Italy are to some extent absorbed by other countries. The total emission of $1965 \mathrm{Mg} \mathrm{yr}^{-1}$ in 2006 is well in the range of total European emissions of $1500-4000 \mathrm{Mg} \mathrm{yr}^{-1}$ estimated by Greally et al. (2007) for the year 2004.

The results for HCFC-141b indicate an ongoing decrease in almost all countries continuing the negative trend observed since about 2002 (Derwent et al., 2007). Different from the two other species, the largest emissions are obtained for France, though these emissions dramatically dropped between 2007 and 2009 by more than a factor of two. A decrease by more than a factor of two is also found for Italy though spread more uniformly over the five years. Total emissions of the 12 countries were almost cut in half between 2006 and 2009 from $1919 \mathrm{Mg} \mathrm{yr}^{-1}$ to $1077 \mathrm{Mg} \mathrm{yr}^{-1}$ which is broadly in line with total European emissions of $3100-4900 \mathrm{Mg} \mathrm{yr}^{-1}$ estimated for the year 2004 using a CO interspecies correlation method or the $5500-6100 \mathrm{Mg} \mathrm{yr}^{-1}$ obtained using the NAME model (Derwent et al., 2007). 
Table 6. Sensitivity of country-specific HFC-125 emissions in 2009 to different inversion settings.

\begin{tabular}{|c|c|c|c|c|c|c|c|c|c|c|c|c|c|c|}
\hline \multirow{2}{*}{$\begin{array}{l}\text { Comment } \\
\text { Reference }\end{array}$} & \multicolumn{2}{|c|}{$\begin{array}{l}\text { Germany } \\
\left(\mathrm{Mg} \mathrm{yr}^{-1}\right)\end{array}$} & \multicolumn{2}{|c|}{$\begin{array}{c}\text { Italy } \\
\left(\mathrm{Mg} \mathrm{yr}^{-1}\right)\end{array}$} & \multicolumn{2}{|c|}{$\begin{array}{c}\text { France } \\
\left(\mathrm{Mg} \mathrm{yr}^{-1}\right)\end{array}$} & \multicolumn{2}{|c|}{$\begin{array}{l}\text { Spain + Port. } \\
\left(\mathrm{Mg} \mathrm{yr}^{-1}\right)\end{array}$} & \multicolumn{2}{|c|}{$\begin{array}{c}\text { U. Kingdom } \\
\left(\mathrm{Mg} \mathrm{yr}^{-1}\right)\end{array}$} & \multicolumn{2}{|c|}{$\begin{array}{c}\text { Ireland } \\
\left(\mathrm{Mg} \mathrm{yr}^{-1}\right)\end{array}$} & \multicolumn{2}{|c|}{ Benelux } \\
\hline & 683 & \pm 80 & 1158 & \pm 128 & 812 & \pm 67 & 861 & \pm 111 & 665 & & 84 & \pm 7 & 235 & \pm 34 \\
\hline Red-noise filter off & 70 & \pm 84 & 1328 & & & & & & & & & & 268 & \pm 35 \\
\hline $10 \times$ higher prior & & \pm 80 & & & & & & & & & & & & \\
\hline $10 \times$ lower prior & 683 & \pm 80 & 1158 & & 312 & \pm 67 & 861 & & 66 & & & \pm 7 & 235 & \pm 34 \\
\hline & & & & & & & & & & & & & & \\
\hline $400 \%$ a priori error & 820 & \pm 102 & 1396 & & 867 & \pm 76 & 779 & \pm 1 & 70 & & 96 & \pm 9 & 248 & \pm 44 \\
\hline Land-sea mask & 747 & \pm 84 & 1291 & \pm 138 & 883 & \pm 69 & 880 & \pm 105 & 73 & \pm 60 & 94 & \pm 7 & 242 & \pm 31 \\
\hline With Monte Cimone & 629 & \pm 72 & 874 & \pm 60 & 747 & \pm 59 & 912 & \pm 84 & 68 & \pm 58 & 85 & \pm 7 & 236 & \pm 32 \\
\hline Hour-of-day filter & 763 & \pm 105 & 1216 & \pm 190 & 794 & \pm 80 & 979 & \pm 148 & 693 & \pm 72 & 81 & \pm 8 & 231 & \pm 42 \\
\hline Keller et al. (2012) & 662 & \pm 99 & 741 & \pm 114 & 512 & \pm 138 & 1109 & \pm 317 & 573 & \pm 91 & 65 & \pm 12 & 187 & \pm 50 \\
\hline
\end{tabular}

\subsection{Sensitivity analysis for HFC-125}

The above results were obtained with a specific inversion setting using for example constant a priori fields. Different configurations, however, may lead to different results which may not necessarily lie within the range of the above stated uncertainties. Therefore, we analyze the sensitivity to different plausible assumptions in order to better explore the solution space and the uncertainties of the method. The analysis is restricted to HFC-125 and results are only presented for the year 2009 as summarized in Table 6. The different settings include (i) switching off of red-noise filter, (ii) application of a land-sea mask, (iii) the effect of 10 times higher or lower a priori emissions, (iv) the effect of more realistic a priori emissions derived from UNFCCC reported country totals spatially distributed proportional to population density, (v) increasing the a-priori uncertainty from 200 to $400 \%$, vi) addition of a third station, Monte Cimone in Italy, and vii) filtering of the measurements for specific hours of the day to reduce potential local effects.

The top row in Table 6 denoted as "reference" is identical to the values in Table 5. Not accounting for autocorrelation in the residuals increases the emission on average by $8 \%$. The largest increase of $15 \%$ is obtained for Italy while emissions from Spain plus Portugal are even slightly reduced. Using 10 times lower or higher constant a priori values, on the other hand, has a negligible effect on the results. A realistic a priori distribution based on UNFCCC country totals also has a comparatively small effect on the results: individual values remain within $7 \%$ of the reference. Increasing the a priori error from $200 \%$ to $400 \%$, on the other hand substantially increases the emissions estimated for Germany and Italy by about $20 \%$ while for the other countries the changes are much smaller.

Applying a land-sea mask on average leads to $8 \%$ higher emissions. The land-sea mask sets the footprints over sea to zero such that only emissions over land can affect the observations. In this way emissions previously assigned to sea surfaces are shifted to the European continent explaining the larger country emissions as compared to the reference. The increase is largest for Italy $(+11 \%)$ most probably due to its long coastline.

Addition of the station Monte Cimone south of the Po Basin in Italy $\left(10.68^{\circ} \mathrm{E} / 44.17^{\circ} \mathrm{N}, 2165 \mathrm{~m}\right.$ a.s.l.), where halocarbons are measured with a GCMS-ADS system similar to the one used at Jungfraujoch until 2008, has the largest impact of all sensitivities tested. Emissions from Italy are reduced by $25 \%$ and the uncertainty is more than halved. It is important to note that adding Monte Cimone does not systematically reduce Italian emissions in all years. For 2006, for example, Italian emissions are increased from $936 \%$ in the reference simulation to $1022 \%$ when including Monte Cimone (not shown). Changes are not restricted to countries in Southern Europe but surprisingly also countries only poorly seen from Monte Cimone are affected. Emissions in Germany, for example, which are mostly constrained by observations from Jungfraujoch, are reduced by $8 \%$ when adding Monte Cimone. Emissions in the UK, Ireland and the Benelux countries, on the other hand, are only little affected as expected. The influence on Germany is probably communicated via Jungfraujoch which is sensitive to emissions from Germany as well as Italy, the latter being significantly altered by the Monte Cimone observations. Note that for the simulations including Monte Cimone a different inversion grid with finer resolution over Italy was used which, however, was almost identical to the reference grid north of the Alps. Emissions in Italy are much better resolved when adding Monte Cimone. Low emissions over the Mediterranean, for example, become much better separated from the higher emissions over the Italian Peninsula (not shown).

Finally, the sensitivity to using only a subset of observations with reduced local influences was tested. Jungfraujoch observations are affected by thermally-induced upward transport of air pollutants on sunny and convective days in spring and summer that are not properly resolved by the model. Since this influence maximizes in the late afternoon and early evening (Collaud Coen et al., 2011) a subset including only measurements between 00:00 UTC and 09:00 UTC 


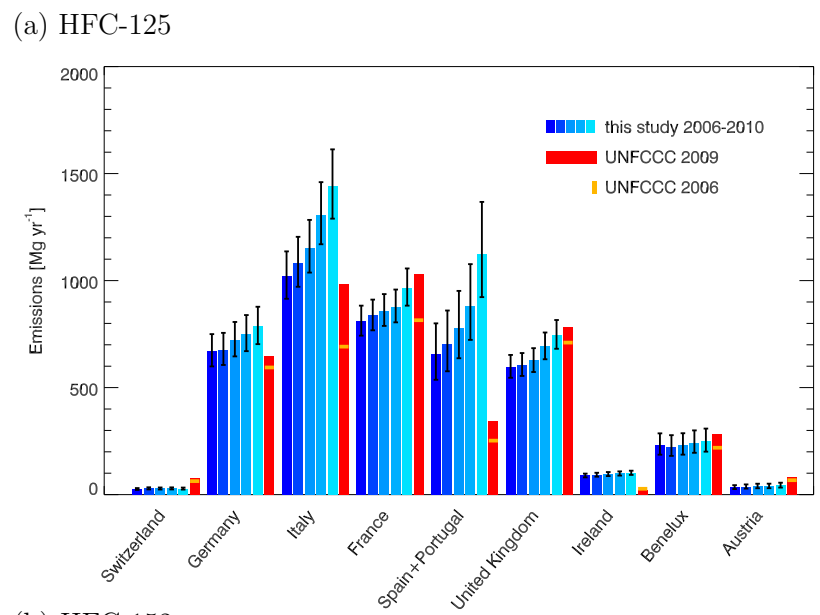

(b) HFC-152a

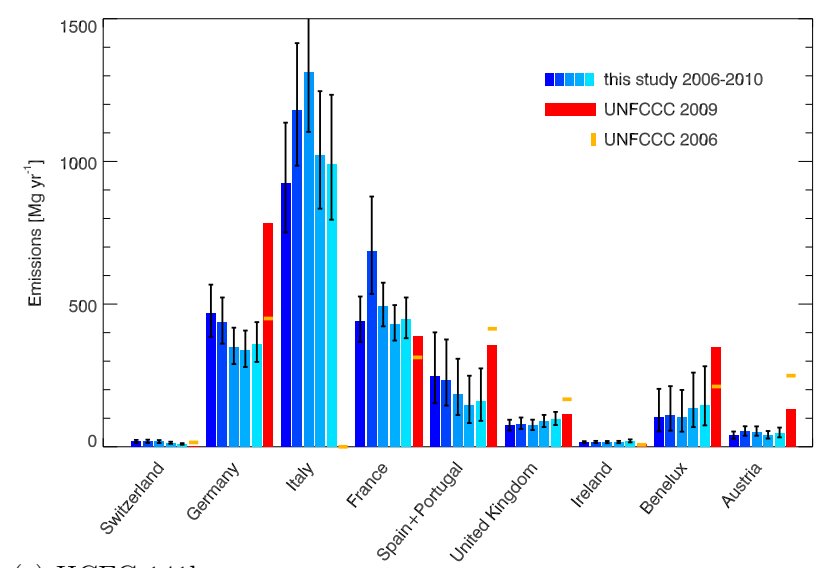

(c) HCFC-141b

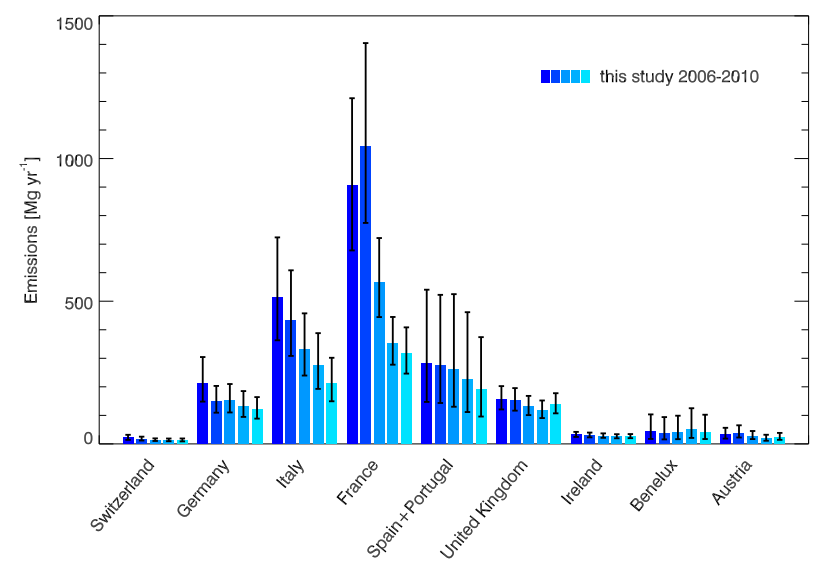

Fig. 11. Evolution of country-specific annual mean emissions of (a) HFC-125, (b) HFC-152a, and (c) HCFC-141b from 2006 to 2009. Blue columns are a posteriori emissions and corresponding $1 \sigma$ uncertainties. Red columns correspond to national emissions reported to UNFCCC for the year 2009. Orange bars are corresponding values for 2006. Reported values are based on National Inventory Submissions 2011 available online at http://unfccc.int. was considered. Measurements at Mace Head, in turn, are more strongly affected by local effects during night, especially under low wind conditions and when the nocturnal boundary layer is low. For Mace Head the subset therefore included only measurements between 09:00 UTC and 18:00 UTC. Comparing the row "Hour-of-day filter" in Table 6 with the reference shows that this filtering has a surprisingly small influence. The main effect is an increase in the uncertainties due to the use of many fewer observations. The absolute values remain within 5\% except for Ireland where the estimate increases by $13 \%$ and for Spain + Portugal where the change is as large as $39 \%$ though the uncertainty of Spanish + Portugese emissions is also very large.

Overall, we can conclude that the country estimates are quite robust to changes in the specific setup of the inversion. The differences between the sensitivity simulations and the reference were generally within the combined uncertainties. Exceptions were the large changes of up to $20-25 \%$ for individual countries obtained when doubling the a-priori uncertainty or adding the site Monte Cimone.

Since the $1 \sigma$ uncertainties of the country-specific emissions are typically of the order of $10 \%$ and the sensitivities to different inversion configurations mostly below $20 \%$, we may conclude that HFC-125 emissions for the countries considered here can be determined to within an uncertainty of about $20 \%$. Note, however, that this uncertainty does not cover potential transport biases since all estimates were based on the same (possibly biased) footprints. Significant biases can be introduced for example by errors in the estimation of boundary layer heights and corresponding vertical mixing (Gerbig et al., 2008). This would be most problematic in cases with strong local sensitivities and emissions but it is probably less relevant for the remote sites considered here. A potentially important source of biases specific for mountain sites, however, is associated with the choice of release height. The study of Folini et al. (2008) investigated the sensitivity of transport simulations for Jungfraujoch to different parameters in a mesoscale Lagrangian particle dispersion model and concluded that the choice of release height had the largest impact on the results. Consistent with their study we find a major reduction of the footprints by on average $40 \%$ when the release height is increased by $580 \mathrm{~m}$ from our preferred height of $3000 \mathrm{~m}$ to the true station altitude of $3580 \mathrm{~m}$. Estimated HFC-125 emissions increase accordingly by approximately $40 \%$ when releasing particles from $3580 \mathrm{~m}$. Assuming that the optimal release height is known only within a range of $\pm 300 \mathrm{~m}$, the uncertainty in emissions associated with this parameter can be roughly estimated to $\pm 20 \%$. A detailed sensitivity study for this critical parameter is beyond the scope of this manuscript but will need to be addressed in the future. 


\subsection{Comparison with Bayesian inversion}

The last row in Table 6 presents country emissions estimated by Keller et al. (2012) using a Bayesian approach similar to the method of Stohl et al. (2009), and using the same FLEXPART model output as used here. Since their study included the measurements from Monte Cimone and the Eastern European site K-Puszta, the numbers may be best compared with the row labeled "With Monte Cimone". Uncertainties reported by Keller et al. (2012) were derived as a maximum of an analytical uncertainty and an uncertainty derived from sensitivity runs and therefore tend to be larger than our estimates. For most countries except Spain + Portugal and Germany the estimates by Keller et al. (2012) are somewhat lower. Emissions from Germany and Italy agree within $8 \%$. Emissions from UK, Ireland, and the Benelux countries are $16 \%, 24 \%$ and $21 \%$ lower than our numbers, respectively, but these differences are within the combined uncertainties and thus not significant. Keller et al. (2012) estimated $22 \%$ higher emissions from Spain + Portugal but they also assigned a large uncertainty to their estimate covering our value. The only significant difference is obtained for France where the estimate of Keller et al. (2012) is $31 \%$ lower than ours. The reason for this discrepancy is presently not known and will require further investigation. Note that our estimate for France is still $19 \%$ below UNFCCC. Our estimates also compare favorably with O'Doherty et al. (2011) for Ireland $\left(85 \pm 7 \mathrm{Mg} \mathrm{yr}^{-1}\right.$ versus $\left.80 \pm 30 \mathrm{Mg} \mathrm{yr}^{-1}\right)$ and the $\mathrm{UK}\left(683 \pm 58 \mathrm{Mg} \mathrm{yr}^{-1}\right.$ versus $\left.730 \pm 170 \mathrm{Mg} \mathrm{yr}^{-1}\right)$. For the region denoted NW EU (=UK, IRL, BENELUX, GER, FRA, DEN) in O'Doherty et al. (2011) our estimate of $2380 \mathrm{Mg} \mathrm{t}^{-1}$ is in between the $3300 \mathrm{Mg} \mathrm{yr}^{-1}$ estimated in that study and the value of $2072 \mathrm{Mg} \mathrm{t}^{-1}$ reported by Keller et al. (2012).

\section{Conclusions}

An inversion method based on an extended Kalman filter was developed to estimate regional scale emissions and their interannual changes of passive or weakly reactive trace gases with positive fluxes from the surface to the atmosphere. For gases like $\mathrm{CO}_{2}$, which do not only have large emission fluxes but also significant uptake at the surface, the method would have to be modified to incorporate negative fluxes and to account for potentially strong temporal variability of surface fluxes. The particular features of the presented method include positive-definiteness of the emissions, the inclusion of measurement-site-specific background concentrations in the state vector to estimate a smoothly varying background per station along with the emission field, and the consideration of temporal correlations in the residuals by applying an augmented state red-noise Kalman filter. The dynamic model describing the evolution of the state vector from one time step to the next assumes persistence of the emissions and allows for a linearly changing background. The covariance matrices describing the model-data mismatch (due to both measurement and transport model errors) and the uncertainty of the state projection are described by a few parameters objectively determined by log-likelihood maximization. A realistic description of these errors is crucial for optimal results and reliable a posteriori uncertainties.

The application of a Kalman filter, which adjusts the emission field through sequential assimilation of observations rather than solving the problem for all observations of a given period at once as done in "batch inversions" (Bruhwiler et al., 2005), allows solving comparatively large inversion problems using conventional computational resources. The computationally limiting part will in most cases be the calculation of the source-receptor-relationships (SRR) with a transport model, not the inversion.

Irrespective of the mathematical details of the method used, the quality of the transport model is a key factor in any inversion study, in particular when addressing regional scale emissions. In our case we employed the Lagrangian particle dispersion model FLEXPART in backward mode driven by ECMWF meteorology at a relatively high resolution of about $20 \times 20 \mathrm{~km}^{2}$ beneficial for simulating transport to stations in a complex environment such as the high alpine site Jungfraujoch.

The inversion method was demonstrated for a series of idealized simulations with synthetic data as well as for estimating emissions of HFC-125, HFC-152a and HCFC-141b in Europe using real observations from Jungfraujoch, Switzerland, and Mace Head, Ireland. For noise-free synthetic observations the solution converged towards the reference field used for generating the synthetic data confirming the correct setup. With increased levels of noise assigned to the synthetic time series the solutions increasingly differed from the true emissions and these differences were shown to be larger when error covariances did not reflect true uncertainties. Accounting for correlated residuals by applying a rednoise Kalman filter clearly improved the agreement with the reference emissions. Seasonal variations and trends imposed on the synthetic backgrounds were successfully traced by the inverted background concentrations and had only little impact on the quality of the emission estimates. Based on simulations with synthetic time series with similar properties as real observations we conclude that differences in countryspecific annual mean emissions need to be larger than about 15-20\% between two different years to be detectable based on observations from Jungfraujoch and Mace Head only.

Estimated emissions of HFC-125 were mostly consistent with bottom-up values as reported to UNFCCC in the framework of the Kyoto Protocol. Both the reported numbers and the inversion showed increasing emissions between 2006 to 2010. Emissions reported by Ireland were significantly lower by a factor of 2-3 with an increasing discrepancy during the latest years. Results for HFC-152a were much more scattered with estimated emissions being significantly lower than reported for Germany, Spain + Portugal, the UK and the 
Benelux countries, but higher for Ireland. Italy, which so far does not report HFC-152a emissions to UNFCCC, showed the highest emissions of all countries considered. HCFC141b showed strongly decreasing emissions in nearly all countries as expected due to its regulation under the Montreal Protocol. Large emissions of the order of $800-1000 \mathrm{Mg} \mathrm{yr}^{-1}$ were estimated for France for the years 2006 and 2007 followed by a sharp decline in the following years. Emissions from Switzerland and Austria seem not to be reliably captured by the inversion probably due to difficulties in simulating transport from the boundary layers of these countries to the high Alpine site Jungfraujoch.

A posteriori $1 \sigma$ uncertainties of country-specific annual emissions were typically in the range of $10-20 \%$ for HFC$125,15-30 \%$ for HFC-152a and 20-40\% for HCFC-141b (Table 5). A sensitivity analysis for HFC-125 indicated that country-specific emissions vary by less than $25 \%$ for different setups of the inversion including varying a-priori distributions and uncertainties, the application of a land-sea mask, and the addition of the station Monte Cimone in Italy. An additional uncertainty specific for HFC-152a is associated with the simulation of its strongly variable background. These uncertainties do not yet account for potential biases in the transport simulations which can be caused by several factors (Manning, 2011). A particularly relevant uncertainty specific for mountain sites is the choice of particle release height. We determined the optimal release height for Jungfraujoch to be around $3000 \mathrm{~m}$ a.s.l. for the model configuration used, but higher or lower release heights within the range of uncertainty would lead to up to $20 \%$ higher or lower emissions, respectively.

Reported country emissions were often outside the uncertainty range of the a posteriori emissions. Together with the fact that for selected countries the agreement between estimated and reported values varies strongly between different compounds, this provides clear evidence for inconsistencies in the bottom-up estimates that can be readily identified by top-down methods.

The method presented here will be compared with other top-down approaches in the framework of the EC FP7 project INGOS. Such a multi-model approach is crucial to improve our understanding of model uncertainties and the ability to derive country-specific estimates. A robust quantification of uncertainties is needed to further strengthen top-down methods as complementary approach to the bottom-up emission estimates (Nisbet and Weiss, 2010).

Acknowledgements. The measurements at Jungfraujoch are part of the Swiss National Air Pollution Monitoring Network (NABEL) and the HALCLIM-project and are supported by the Swiss Federal Office for the Environment (FOEN). We also acknowledge the International Foundation "High Altitude Research Stations Jungfraujoch and Gornergrat" for providing an excellent infrastructure. The operation of the Mace Head station was supported by the Department of the Energy and Climate Change (DECC, UK) (contracts GA01081 and GA01103 to the University of
Bristol). The Swiss National Science Foundation is acknowledged for partly financing the IPAZIA computational cluster (project 206021_128754) on which FLEXPART calculations were performed.

Edited by: N. Harris

\section{References}

Baker, D. F., Law, R. M., Gurney, K. R., Rayner, P., Peylin, P., Denning, A. S., Bousquet, P., Bruhwiler, L., Chen, Y. H., Ciais, P., Fung, I. Y., Heimann, M., John, J., Maki, T., Maksyutov, S., Masarie, K., Prather, M., Pak, B., Taguchi, S., and Zhu, Z.: TransCom 3 inversion intercomparison: impact of transport model errors on the interannual variability of regional $\mathrm{CO}_{2}$ fluxes, 1988-2003, Global Biogeochem. Cy., 20, GB1002, doi:10.1029/2004GB002439, 2006.

Bergamaschi, P., Krol, M., Dentener, F., Vermeulen, A., Meinhardt, F., Graul, R., Ramonet, M., Peters, W., and Dlugokencky, E. J.: Inverse modelling of national and European $\mathrm{CH}_{4}$ emissions using the atmospheric zoom model TM5, Atmos. Chem. Phys., 5, 2431-2460, doi:10.5194/acp-5-2431-2005, 2005.

Bousquet, P.: Methane sources and sinks of the past two decades: what did we learn with atmospheric inversions?, 19th Annual VM Goldschmidt Conference, Davos, Switzerland, 21 June 2009, Geochim. Cosmochim. Ac., 73, A149, 2009.

Bousquet, P., Ciais, P., Miller, J. B., Dlugokencky, E. J., Hauglustaine, D. A., Prigent, C., Van der Werf, G. R., Peylin, P., Brunke, E. G., Carouge, C., Langenfelds, R. L., Lathiere, J., Papa, F., Ramonet, M., Schmidt, M., Steele, L. P., Tyler, S. C., and White, J.: Contribution of anthropogenic and natural sources to atmospheric methane variability, Nature, 443, 439-443, doi:10.1038/nature05132, 2006.

Bruhwiler, L. M. P., Michalak, A. M., Peters, W., Baker, D. F., and Tans, P.: An improved Kalman Smoother for atmospheric inversions, Atmos. Chem. Phys., 5, 2691-2702, doi:10.5194/acp-52691-2005, 2005.

Brunner, D., Staehelin, J., Künsch, H. R., and Bodeker, G. E.: A Kalman filter reconstruction of the vertical ozone distribution in an equivalent latitude - potential temperature framework from TOMS/GOME/SBUV total ozone observations, J. Geophys. Res., 111, D12308, doi:10.1029/2005JD006279, 2006.

Chen, Y.-H. and Prinn, R. G.: Estimation of atmospheric methane emissions between 1996 and 2001 using a three-dimensional global chemical transport model, J. Geophys. Res., 111, D10307, doi:10.1029/2005JD006058, 2006.

Collaud Coen, M., Weingartner, E., Furger, M., Nyeki, S., Prévôt, A. S. H., Steinbacher, M., and Baltensperger, U.: Aerosol climatology and planetary boundary influence at the Jungfraujoch analyzed by synoptic weather types, Atmos. Chem. Phys., 11, 5931-5944, doi:10.5194/acp-11-5931-2011, 2011.

Cunnold, D. M., Fraser, P. J., Weiss, R. F., Prinn, R. G., Simmonds, P. G., Miller, B. R., Alyea, F. N., and Crawford, A. J.: Global trends and annual releases of $\mathrm{CCl}_{3} \mathrm{~F}$ and $\mathrm{CCl}_{2} \mathrm{~F}_{2}$ estimated from ALE/GAGE and other measurements from July 1978 to June 1991, J. Geophys. Res., 99, 1107-1126, 1994.

Derwent, R. G., Simmonds, P. G., Greally, B. R., O'doherty, S., McCulloch, A., Manning, A., Reimann, S., Folini, D., and 
Vollmer, M. K.: The phase-in and phase-out of European emissions of HCFC-141b and HCFC-142b under the Montreal Protocol: evidence from observations at Mace Head, Ireland and Jungfraujoch, Switzerland from 1994 to 2004, Atmos. Environ., 41, 757-767, doi:10.1016/j.atmosenv.2006.09.009, 2007.

Engelen, R. J., Denning, A. S., Gurney, K. R., Law, R. M., Denning, A. S., Rayner, P. J., Baker, D., Bousquet, P., Bruhwiler, L., Chen, Y. H., Ciais, P., Fan, S., Fung, I. Y., Gloor, M., Heimann, M., Higuchi, K., John, J., Maki, T., Maksyutov, S., Masarie, K., Peylin, P., Prather, M., Pak, B. C., Sarmiento, J., Taguchi, S., Takahashi, T., and Yuen, C. W.: On error estimation in atmospheric $\mathrm{CO}_{2}$ inversions, J. Geophys. Res., 111, D14199, doi:10.1029/2006JD007428, 2006.

Folini, D., Ubl, S., and Kaufmann, P.: Lagrangian particle dispersion modeling for the high Alpine site Jungfraujoch, J. Geophys. Res., 113, D18111, doi:10.1029/2007JD009558, 2008.

Gerbig, C., Körner, S., and Lin, J. C.: Vertical mixing in atmospheric tracer transport models: error characterization and propagation, Atmos. Chem. Phys., 8, 591-602, doi:10.5194/acp-8591-2008, 2008.

Göckede, M., Michalak, A. M., Vickers, D., Turner, D. P., and Law, B. E.: Atmospheric inverse modeling to constrain regionalscale $\mathrm{CO}_{2}$ budgets at high spatial and temporal resolution, J. Geophys. Res., 115, D15113, doi:10.1029/2009JD012257, 2010.

Greally, B. R., Manning, A. J., Reimann, S., McCulloch, A., Huang, J., Dunse, B. L., Simmonds, P. G., Prinn, R. G., Fraser, P. J., Cunnold, D. M., O'Doherty, S., Porter, L. W., Stemmler, K., Vollmer, M. K., Lunder, C. R., Schmidbauer, N., Hermansen, O., Arduini, J., Salameh, P. K., Krummel, P. B., Wang, R. H. J., Folini, D., Weiss, R. F., Maione, M., Nickless, G., Stordal, F., and Derwent, R. G.: Observations of 1,1-difluoroethane (HFC-152a) at AGAGE and SOGE monitoring stations in 1994-2004 and derived global and regional emission estimates, J. Geophys. Res., 112, D06308, doi:10.1029/2006JD007527, 2007.

Gurney, K. R., Law, R. M., Denning, A. S., Rayner, P. J., Baker, D., Bousquet, P., Bruhwiler, L., Chen, Y. H., Ciais, P., Fan, S., Fung, I. Y., Gloor, M., Heimann, M., Higuchi, K., John, J., Maki, T., Maksyutov, S., Masarie, K., Peylin, P., Prather, M., Pak, B. C., Randerson, J., Sarmiento, J., Taguchi, S., Takahashi, T., and Yuen, C. W.: Towards robust regional estimates of $\mathrm{CO}_{2}$ sources and sinks using atmospheric transport models, Nature, 415, 626-630, 2002.

Hartley, D. and Prinn, R.: Feasibility of determining surface emissions of trace gases using an inverse method in a threedimensional chemical transport model, J. Geophys. Res., 98, 5183-5197, 1993.

Harvey, A. C.: Forecasting, Structural Time Series Models and the Kalman Filter, Cambridge University Press, New York, USA, 1989.

Henne, S., Furger, M., and Prévôt, A. S. H.: Climatology of mountain venting induced moisture layers in the lee of the Alps, J. Appl. Meteorol., 44, 620-633, 2005.

Henne, S., Brunner, D., Folini, D., Solberg, S., Klausen, J., and Buchmann, B.: Assessment of parameters describing representativeness of air quality in-situ measurement sites, Atmos. Chem. Phys., 10, 3561-3581, doi:10.5194/acp-10-3561-2010, 2010.

Hirsch, A. I., Michalak, A. M., Bruhwiler, L. M., Peters, W., Dlugokencky, E. J., and Tans, P. P.: Inverse modeling estimates of the global nitrous oxide surface flux from 1998-2001, Global Biogeochem. Cy., 20, GB1008, doi:10.1029/2004GB002443, 2006.

Houweling, S., Kaminski, T., Dentener, F., Lelieveld, J., and Heimann, M.: Inverse modeling of methane sources and sinks using the adjoint of a global transport model, J. Geophys. Res., 104, 26137-26160, 1999.

Kalman, R. H. and Bucy, R. S.: New results in linear filtering and prediction theory, J. Basic Eng., 83D, 95-108, 1961.

Kaminski, T., Rayner, P. J., Heimann, M., and Enting, I. G.: On aggregation errors in atmospheric transport inversions, J. Geophys. Res., 106, 4703-4715, 2001.

Keller, C. A., Brunner, D., Henne, S., Vollmer, M. K., O'Doherty, S., and Reimann, S.: Evidence for underreported Western European emissions of the potent greenhouse gas HFC-23, Geophys. Res. Lett., 38, L15808, doi:10.1029/2011GL047976, 2011.

Keller, C. A., Hill, M., Vollmer, M. K., Henne, S., Brunner, D., Reimann, S., O’Doherty, S., Maione, M., Ferenczi, Z., Haszpra, L., Manning, A. J., and Peter, T.: European emissions of halogenated greenhouse gases inferred from atmospheric measurements, Environ. Sci. Technol., 46, 217-225, 2012.

Lin, J. C. and Gerbig, C.: Accounting for the effect of transport errors on tracer inversions, Geophys. Res. Lett., 32, L01802, doi:10.1029/2004GL021127, 2005.

Mahowald, N. M., Prinn, R. G., and Rasch, P. J.: Deducing $\mathrm{CCl}_{3} \mathrm{~F}$ emissions using an inverse method and chemical transport models with assimilated winds, J. Geophys. Res., 102, 28153-28168, 1997.

Manning, A. J.: The challenge of estimating regional trace gas emissions from atmospheric observaions, Phil. Trans. R. Soc. A, 369, 1943-1954, doi:10.1098/rsta.2010.0321, 2011.

Manning, A. J., Ryall, D. B., Derwent, R. G., Simmonds, P. G., and O'Doherty, S.: Estimating European emissions of ozonedepleting and greenhouse gases using observations and a modeling back-attribution technique, J. Geophys. Res., 108, 4405, doi:10.1029/2002JD002312, 2003.

Manning, A. J., O’Doherty, S., Jones, A. R., Simmonds, P. G., and Derwent, R. G.: Estimating UK methane and nitrous oxide emissions from 1990 to 2007 using an inversion modeling approach, J. Geophys. Res., 116, D02305, doi:10.1029/2010JD014763, 2011.

Miller, B. R., Weiss, R. F., Salameh, P. K., Tanhua, T., Greally, B. R., Mühle, J., and Simmonds, P. G.: Medusa: a sample preconcentration and GC/MS detector system for in situ measurements of atmospheric trace halocarbons, hydrocarbons, and sulfur compounds, Anal. Chem., 80, 1536-1545, doi:10.1021/ac702084k, 2008.

Montzka, S. A., Butler, J. H., Elkins, J. W., Thompson, T. M., Clarke, A. D., and Lock, L. T.: Present and future trends in the atmospheric burden of ozone-depleting halogens, Nature, 398, 690-694, doi:10.1038/19499, 1999.

Mulquiney, J. E., Taylor, J. A., Jakeman, A. J., Norton, J. P., and Prinn, R. G.: A new inverse method for trace gas flux estimation. 2. Application to tropospheric $\mathrm{CFCl}_{3}$ fluxes, J. Geophys. Res., 103, 1429-1442, doi:10.1029/97JD01811, 1998.

Nisbet, E., Weiss, R.: Top-down versus bottom-up, Science, 328, 1241-1243, doi:10.1126/science.1189936, 2010.

Nyeki, S., Kalberer, M., Colbeck, I., De Wekker, S., Furger, M., Gaggeler, H. W., Kossmann, M., Lugauer, M., Steyn, D., Wein- 
gartner, E., Wirth, M., and Baltensperger, U.: Convective boundary layer evolution to $4 \mathrm{~km}$ asl over high-alpine terrain: airborne lidar observations in the Alps, Geophys. Res. Lett., 27, 689-692, 2000.

O'Doherty, S., Cunnold, D., Sturrock, G. A., Ryall, D., Derwent, R. G., Wang, R. H. J., Simmonds, P., Fraser, P. J., Weiss, R. F., Salameh, P., Miller, B. R., and Prin, R. G.: In-Situ Chloroform Measurements at AGAGE Atmospheric Research Stations from 1994-1998., J. Geophys. Res., 106, 20429-20444, 2001.

O’Doherty, S., Cunnold, D. M., Miller, B. R., Mühle, J., McCulloch, A., Simmonds, P. G., Manning, A. J., Reimann, S., Vollmer, M. K., Greally, B. R., Prinn, R. G., Fraser, P. J., Steele, L. P., Krummel, P. B., Dunse, B. L., Porter, L. W., Lunder, C. R., Schmidbauer, N., Hermansen, O., Salameh, P. K., Harth, C. M., Wang, R. H. J., and Weiss, R. F.: Global and regional emissions of $\mathrm{HFC}-125\left(\mathrm{CHF}_{2} \mathrm{CF}_{3}\right)$ from in situ and air archive atmospheric observations at AGAGE and SOGE observatories, J. Geophys. Res., 114, D23304, doi:10.1029/2009JD012184, 2009.

O’Doherty, S., Simmonds, P., Grant, A., Manning, A. J., Athanassiadou, M., and Derwent, R. G.: Interpretation of long-term measurements of radiatively active trace gases and ozone depleting substances, DECC contract numbers: GA1103 and GA0201, Department of Energy and Climate Change (DECC), available at: http://www.decc.gov.uk/assets/decc/11/stats/climate-change/ 2143-radiatively-active-trace-gases-pt2.pdf, 2011.

Olivier, J., Berdowski, J., Peters, J., Bakker, J., Visschedijk, A., and Bloos, J.: Applications of EDGAR including a description of EDGAR V3.0: reference database with trend data for 19701995, NRP Report 410200 051, RIVM, Bilthoven, The Netherlands, 2002.

Press, W. H., Teukolsky, S. A., Vetterling, W. T., and Flannery, B. P.: Numerical Recipes, The Art of Scientific Computing, 3rd edn., Cambridge University Press, New York, NY, USA, 2007.

Prinn, R. G., Weiss, R. F., Fraser, P. J., Simmonds, P. G., Cunnold, D. M., Alyea, F. N., O'Doherty, S., Salameh, P., Miller, B. R., Huang, J., Wang, R. H. J., Hartley, D. E., Harth, C., Steele, L. P., Sturrock, G., Midgley, P. M., and McCulloch, A.: A history of chemically and radiatively important gases in air deduced from ALE/GAGE/AGAGE, J. Geophys. Res., 105, 17751-17792, 2000.

Rayner, P. J., Law, R. M., Allison, C. E., Francey, R. J., Trudinger, C. M., and Pickett-Heaps, C.: Interannual variability of the global carbon cycle (1992-2005) inferred by inversion of atmospheric $\mathrm{CO}_{2}$ and delta $\left(\mathrm{CO}_{2}\right)-\mathrm{C}-13$ measurements, Global Biogeochem. Cy., 22, GB3008, doi:10.1029/2007GB003068, 2008.

Reimann, S., Vollmer, M. K., Folini, D., Steinbacher, M., Hill, M., Buchmann, B., Zander, R., and Mahieu, E.: Observations of long-lived anthropogenic halocarbons at the high-Alpine site of Jungfraujoch (Switzerland) for assessment of trends and European sources, International Conference Celebrating the 75th Anniversary of the High Altitude Research Station Jungfraujoch, Interlaken, Switzerland, Sep 11-13, 2006, Sci. Total Environ., 391, 224-231, doi:10.1016/j.scitotenv.2007.10.022, 2008.

Rigby, M., Manning, A. J., and Prinn, R. G.: Inversion of long-lived trace gas emissions using combined Eulerian and Lagrangian chemical transport models, Atmos. Chem. Phys., 11, 9887-9898, doi:10.5194/acp-11-9887-2011, 2011.

Rödenbeck, C., Conway, T. J., and Langenfelds, R. L.: The effect of systematic measurement errors on atmospheric $\mathrm{CO}_{2}$ inversions: a quantitative assessment, Atmos. Chem. Phys., 6, 149161, doi:10.5194/acp-6-149-2006, 2006.

Rödenbeck, C., Gerbig, C., Trusilova, K., and Heimann, M.: A twostep scheme for high-resolution regional atmospheric trace gas inversions based on independent models, Atmos. Chem. Phys., 9, 5331-5342, doi:10.5194/acp-9-5331-2009, 2009.

Seibert, P. and Frank, A.: Source-receptor matrix calculation with a Lagrangian particle dispersion model in backward mode, Atmos. Chem. Phys., 4, 51-63, doi:10.5194/acp-4-51-2004, 2004.

Seibert, P., Kromp-Kolb, H., Kasper, A., Kalina, M., Puxbaum, H., Jost, D., Schwikowski, M., and Baltensperger, U.: Transport of polluted boundary layer air from the Po Valley to high-alpine sites, Atmos. Environ., 32, 3953-3965, 1998.

Simmonds, P. G., O'Doherty, S., Nickless, G., Sturrock, G. A., Swaby, R., Knight, P., Ricketts, J., Woffendin, G., and Smith, R.: Automated gas chromatograph mass spectrometer for routine atmospheric field measurements of the CFC Replacement Compounds, the hydrofluorocarbons and hydrochlorofluorocarbons, Anal. Chem., 67, 717-723, 1995.

Simon, D.: Optimal State Estimation: Kalman, H-infinity, and Nonlinear Approaches, John Wiley \& Sons, Hoboken, New Jersey, USA, 526 pp., 2006.

Stohl, A., Forster, C., Frank, A., Seibert, P., and Wotawa, G.: Technical note: The Lagrangian particle dispersion model FLEXPART version 6.2, Atmos. Chem. Phys., 5, 2461-2474, doi:10.5194/acp-5-2461-2005, 2005.

Stohl, A., Seibert, P., Arduini, J., Eckhardt, S., Fraser, P., Greally, B. R., Lunder, C., Maione, M., Mühle, J., O’Doherty, S., Prinn, R. G., Reimann, S., Saito, T., Schmidbauer, N., Simmonds, P. G., Vollmer, M. K., Weiss, R. F., and Yokouchi, Y.: An analytical inversion method for determining regional and global emissions of greenhouse gases: sensitivity studies and application to halocarbons, Atmos. Chem. Phys., 9, 1597-1620, doi:10.5194/acp-9-1597-2009, 2009.

Stohl, A., Kim, J., Li, S., O’Doherty, S., Mühle, J., Salameh, P. K., Saito, T., Vollmer, M. K., Wan, D., Weiss, R. F., Yao, B., Yokouchi, Y., and Zhou, L. X.: Hydrochlorofluorocarbon and hydrofluorocarbon emissions in East Asia determined by inverse modeling, Atmos. Chem. Phys., 10, 3545-3560, doi:10.5194/acp-10-3545-2010, 2010.

Velders, G. J. M., Fahey, D. W., Daniel, J. S., McFarland, M., and Andersen, S. O.: The large contribution of projected HFC emissions to future climate forcing, P. Natl. Acad. Sci. USA, 106, 10949-10954, doi:10.1073/pnas.0902817106, 2009.

Villani, M. G., Bergamaschi, P., Krol, M., Meirink, J. F., and Dentener, F.: Inverse modeling of European $\mathrm{CH}_{4}$ emissions: sensitivity to the observational network, Atmos. Chem. Phys., 10, 1249-1267, doi:10.5194/acp-10-1249-2010, 2010.

Vollmer, M. K., Reimann, S., Folini, D., Porter, L. W., and Steele, L. P.: First appearance and rapid growth of anthropogenic HFC-245fa $\left(\mathrm{CHF}_{2} \mathrm{CH}_{2} \mathrm{CF}_{3}\right)$ in the atmosphere, Geophys. Res. Lett., 33, L20806, doi:10.1029/2006GL026763, 2006.

Vollmer, M. K., Zhou, L. X., Greally, B. R., Henne, S., Yao, B., Reimann, S., Stordal, F., Cunnold, D. M., Zhang, X. C., Maione, M., Zhang, F., Huang, J., and Simmonds, P. G.: Emissions of ozone-depleting halocarbons from China, Geophys. Res. 
Lett., 36, L15823, doi:10.1029/2009GL038659, 2009.

Winiwarter, W. and Rypdal, K.: Assessing the uncertainty associated with national greenhouse gas emission inventories, Atmos. Environ., 35, 5425-5440, 2001.
World Meteorological Organization: Scientific Assessment of Ozone Depletion: 2006, Global Ozone Research and Monitoring Project, Report No. 50, Geneva, Switzerland, 2007. 